University of Wollongong

Research Online

Faculty of Business - Papers (Archive)

Faculty of Business and Law

$1-1-2015$

Pollution diffusion and abatement activities across space and over time

Davide La Torre

University of Milan, Khalifa University

Danilo Liuzzi

University of Milan

Simone Marsiglio

University of Wollongong, simonem@uow.edu.au

Follow this and additional works at: https://ro.uow.edu.au/buspapers

Part of the Business Commons

Research Online is the open access institutional repository for the University of Wollongong. For further information contact the UOW Library: research-pubs@uow.edu.au 


\title{
Pollution diffusion and abatement activities across space and over time
}

\begin{abstract}
We analyze the spatio-temporal dynamics of capital and pollution in an economic growth model with purposive environmental protection activities. The production process of a unique homogeneous good generates pollution, thus the increases in output associated with economic growth tend to rise the stock of pollution. Pollution is a negative production externality which thus feeds back on the economy lowering the level of output; in order to compensate for such a negative effect associated with economic development, pollution is reduced by publicly funded abatement activities. We firstly consider a Solowtype framework in which economic and environmental policies are completely exogenous, and then we move to a Ramsey-type context in which they are endogenously determined. We analyze the spatiotemporal dynamics of the model economy through numerical simulations, and we consider two different specifications of the production function (a globally concave and a convex-concave technology) in order to stress the role that eventual poverty traps might play on both economic and environmental outcomes. We show that in the convex-concave technology framework, whenever rich regions are substantially rich diffusion can help poor regions to escape their poverty traps; if however they are not rich enough diffusion might condemn also rich regions to collapse. However, even if rich regions are particularly rich whenever the pollution externality is strong, the whole spatial economy might be doomed to collapse.
\end{abstract}

\section{Keywords}

abatement, diffusion, time, pollution, over, space, across, activities

\section{Disciplines}

Business

\section{Publication Details}

La Torre, D., Liuzzi, D. \& Marsiglio, S. (2015). Pollution diffusion and abatement activities across space and over time. Mathematical Social Sciences, 78 48-63. 


\title{
Pollution Diffusion and Abatement Activities across Space and over Time*
}

\author{
Davide La Torre ${ }^{\dagger} \quad$ Danilo Liuzzi ${ }^{\ddagger} \quad$ Simone Marsiglio ${ }^{\S}$ \\ Forthcoming in Mathematical Social Sciences
}

\begin{abstract}
We analyze the spatio-temporal dynamics of capital and pollution in an economic growth model with purposive environmental protection activities. The production process of a unique homogeneous good generates pollution, thus the increases in output associated with economic growth tend to rise the stock of pollution. Pollution is a negative production externality which thus feeds back on the economy lowering the level of output; in order to compensate for such a negative effect associated with economic development, pollution is reduced by publicly funded abatement activities. We firstly consider a Solow-type framework in which economic and environmental policies are completely exogenous, and then we move to a Ramseytype context in which they are endogenously determined. We analyze the spatio-temporal dynamics of the model economy through numerical simulations, and we consider two different specifications of the production function (a globally concave and a convex-concave technology) in order to stress the role that eventual poverty traps might play on both economic and environmental outcomes. We show that in the convex-concave technology framework, whenever rich regions are substantially rich diffusion can help poor regions to escape their poverty traps; if however they are not rich enough diffusion might condemn also rich regions to collapse. However, even if rich regions are particularly rich whenever the pollution externality is strong, the whole spatial economy might be doomed to collapse.
\end{abstract}

Keywords: Economic Growth, Pollution, Spatial Dynamics, Poverty Traps

JEL Classification: C60, O40, Q50

\section{Introduction}

Understanding the mutual implications between economic activities and environmental degradation has been an important research topic for the last decades (Solow, 1974; Stokey, 1998). Nowadays also policymakers seem to agree that some concrete effort is needed to effectively promote sustainable development (UNEP, 2012), thus the question has become even more relevant than ever. Much attention in literature is placed on the joint evolution of capital and pollution, looking for conditions ensuring that sustainable growth is actually possible (see Xepapadeas, 2005, for a survey; or, among others, Gradus and Smulders, 1993; Bovenberg and Smulders, 1995; Brock and Taylor, 2010). To the best of our knowledge, all the existing works focus only on the temporal economic and environmental dynamics without considering their spatial interaction. This

\footnotetext{
${ }^{*}$ We are grateful to Olewaseun Sharomi for his precious support on the numerical analysis. We also wish to thank the participants to the EAERE 2015 Conference (Helsinki, Finland) for helpful feedback and suggestions. We are indebted to two anonymous referees for their constructive comments helping us to substantially improve our paper. All remaining errors and omissions are our own sole responsibility.

${ }^{\dagger}$ Khalifa University, Department of Applied Mathematics and Science, Abu Dhabi, UAE and University of Milan, Department of Economics, Business and Statistics, Milan, Italy. Contact: davide.latorre@kustar.ac.ae

${ }^{\ddagger}$ University of Milan, Department of Economics, Business and Statistics, Milan, Italy. Contact: danilo.liuzzi@unimi.it

$\S$ University of Wollongong, School of Accounting, Economics and Finance, Northfields Avenue, Wollongong 2522 NSW, Australia. simonem@uow.edu.au
} 
is clearly a strong limitation since pollution is a global phenomenon with no geographical barriers and not restricted within national borders. Moreover, since the typical macroeconomic framework is constructed around a representative agent, it is not possible to analyze how the behavior of certain individuals might affect the behavior of others located in different venues. In order to more realistically describe the world's environmental problems, it is then essential to extend the analysis to a spatial dimension. This is the goal of this paper which thus wishes to shed some light on the joint spatio-temporal evolution of capital and pollution. Since no other paper tries to analyze such a complex and delicate issue, it seems convenient to focus on the simplest possible framework. Specifically, we first consider a Solow-type (1956) model, where agents' decisions are exogenously given. However, the choices of agents in different locations affect one another through a certain diffusion term. Our approach is similar to Brock and Taylor's (2010) in their celebrated green Solow model. With respect to them in order to maintain the model simple we do not allow for (cleaning) technological progress, but we assume that a certain amount of resources is devoted to pollution abatement activities. This means that the saving and environmental protection behavior is exogenous, and agents' spatial heterogeneity is crucial in determining capital and pollution accumulation. After analyzing such a Solow-type framework, we consider a Ramsey (1928) version of the problem in which economic and environmental policies (i.e., consumption and abatement) are endogenously determined.

This work tries to combine the macroeconomic and economic geography literature with the growth and environment literature. The growth and environment literature is quite dated and wide (see Smulders, 1999, for a survey), and it mainly shows that in the one-sector framework growth and environment may be compatible or not according to the relative size of the crowding out and productivity effects (Smulders, 1999). The former effect refers to the amount of resources that needs to be subtracted from capital investment in order to protect the environment, while the latter to the potential effects that the environment may induce on production. The macroeconomic and economic geography literature is instead limited and recent. After the seminal works of Krugman $(1991,1992)$ analyzing spatial dynamic models to highlight the importance of economic geography models. Camacho and Zou (2004) extend the classical Solow model to the spatial dimension to allow some heterogeneity across different locations, showing the existence of and convergence to a stationary solution. Brito (2004) and Boucekkine et al. (2009) deal with a similar spatial extension of the classical Ramsey model, by focusing on the problems that may arise in a framework of optimal control when the state equations are parabolic differential equations 2 . While all the previous works adopt a neoclassical Cobb-Douglas production technology, Boucekkine et al. (2013b) consider an AK framework allowing to derive an analytical expression for the optimal capital dynamics showing that the spatial structure implies convergence in the capital level across locations even if the returns to capital are constant. Our work is also partly related to another line of research which analyzes the spatial implications and the eventual emergence of patterns and agglomerations in environmental and ecological economics models. Brock and Xepapadeas (2008, 2010) characterize under which conditions diffusion can generate or destroy spatial heterogeneity and agglomeration, with or without the presence of an optimizing planner. Camacho and Pérez-Barahona (2015) study a problem of optimal land use in the presence of local and global pollution, where land is immobile by nature but local actions affect the whole space since pollution flows across locations.

Our paper borrows from all these literatures by analyzing the growth and pollution nexus in a context of spatial heterogeneity in which both capital and pollution diffuse across space and accumulate over time. Specifically, the spatio-temporal dynamics of capital is similar to what considered in the macroeconomics and economic geography literature (Boucekkine et al., 2009), while the spatio-temporal dynamics of pollution

\footnotetext{
${ }^{1}$ The economic geography literature studies the location, distribution and spatial organization of economic activities across the real world. In particular, it finds out that economic activity is strongly concentrated in a small proportion of the planet's surface, and such a concentration exists not only at world level, but also at several other levels: on metropoli or coasts, within countries, or on particular locations, for many industries (see Fujita et al., 1999; and Fujita and Thisse, 2002).

${ }^{2}$ On the control of partial differential equations arising in the economic growth framework, see also Boucekkine et al. (2013a)
} 
is consistent with the spatial environmental literature (Camacho and Pérez-Barahona, 2015); the mutual interaction between economic and abatement activities and pollution is enriched according to the feedback externality considered in the growth and environment literature (Smulders, 1999). Indeed, we consider a spatial model where agents are located across a linear city, and economic production has the side effect of generating emissions which increase the stock of pollution, and pollution represents a negative production externality, which therefore reduces capital accumulation. Thus crowding out capital investments will not only reduce pollution but will also allow to alleviate its negative impact on output, due to a negative productivity effect. We assume that green activities are financed by the tax revenue (capital investments are subject to taxation) and these abatement efforts allow to reduce a certain share of locally generated emissions. The dynamics of both capital and pollution is not trivial since pollution generated in a certain location will affect also the productivity in other locations, via both diffusive and non diffusive mechanisms.

The paper proceeds as follows. Section 2 introduces our spatial Solow-type model, summarized by two partial differential equations describing the capital and pollution diffusion, respectively. Since closed form solutions cannot be derived, in section 3 we explore the model's outcome through numerical simulations under two alternative scenarios; the first case considers the traditional concave Cobb-Douglas production function while the second one a convex-concave technology in order to represent the growth and environment problems in developed and developing countries, respectively (see Skiba, 1978). We compare the model's outcome under these two different production technology specifications and under different intensities of the diffusion parameters, showing that higher degrees of diffusion can dampen the convergence effects implied by diminishing marginal returns in capital accumulation. Moreover, we show that in the convex-concave production framework the spatial implications of capital and pollution, thanks to two different channels (namely, diffusion and pollution externality), might allow poor regions to escape their poverty traps (or alternatively, it might condemn also rich regions to collapse in the long run). Section 4 presents the Ramsey (1928) version of our problem, where the social planner optimally determines consumption and the environmental policy instrument, thus the economy is summarized by an optimal control problem in which the state equations are two partial differential equations. We compare such an optimally planned outcome with what discussed in the previous section highlighting the effects of (optimal) policymaking on the economic and environmental outcomes. Section 5 as usual concludes and proposes directions for future research. Technical details about the algorithm used to perform our numerical simulations are discussed in appendix $\mathrm{A}$.

\section{The Solow-Type Model}

We introduce a spatial component in the Solow model, following the approach in Brito (2004), Camacho and Zou (2004), and Camacho et al. (2008). In particular, we assume a continuous space structure to represent that the economy develops along a linear city (see Hotelling, 1929), where not only capital diffuses across different locations but also pollution, even if generated in a specific location, diffuses over the whole economy (Camacho and Pérez-Barahona, 2015). Therefore $k(x, t)$ and $p(x, t)$ denote respectively the capital stock held by and the pollution stock faced by a representative household located in the position $x$ at date $t$, in a compact interval $\left[x_{a}, x_{b}\right] \subset \mathbb{R}$, and $t \geq 0$. We abstract from population growth and without loss of generality the population size is normalized to unity. We also assume that the initial capital and pollution distribution, $k(x, 0)$ and $p(x, 0)$, are known and there is no capital or pollution flow through the boundary of $\left[x_{a}, x_{b}\right]$ namely the directional derivative is null, $\frac{\partial k(x, t)}{\partial x}=\frac{\partial p(x, t)}{\partial x}=0$, at $x=x_{a}$ and $x=x_{b}$. The 
spatio-temporal dynamic model is summarized by the following system of partial differential equations:

$$
\begin{aligned}
\frac{\partial k(x, t)}{\partial t} & =d_{k} \frac{\partial^{2} k(x, t)}{\partial x^{2}}+\frac{s(x) f[k(x, t)][1-\tau(x)]}{d[k(x, t)]}-\delta_{k} k(x, t) . \\
& =d_{k} \frac{\partial^{2} k(x, t)}{\partial x^{2}}+\frac{s(x) f[k(x, t)][1-u(x)]^{\epsilon}}{a+b[p(x, t)]^{2}}-\delta_{k} k(x, t) . \\
\frac{\partial p(x, t)}{\partial t} & =d_{p} \frac{\partial^{2} p(x, t)}{\partial x^{2}}+\theta \int_{x_{a}}^{x_{b}}\left[1-u\left(x^{\prime}\right)\right] f\left[k\left(x^{\prime}, t\right)\right] \varphi\left(x^{\prime}, x\right) d x^{\prime}-\delta_{p} p(x, t) .
\end{aligned}
$$

Equation (1) describes the evolution of capital. The functions $s(x)$ and $\tau(x)$ describe the savings rate and the environmental tax rate at the location $x$, respectively; note that they are assumed to be constant over time but heterogenous across space. The production technology $f[k(x, t)]$ uses only capital as an input thus pollution is not a factor of production; however, pollution reduces the level of output through the following damage function $d[k(x, t)]=a+b[p(x, t)]^{2}$. This specification states that in absence of pollution the production externality is totally irrelevant while as pollution increases output falls more than proportionally. The production technology will be specified as being globally concave or convex-concave later. The local government levies taxes proportional to capital investments to finance environmental protection activities; we assume it wishes to maintain a balanced budget at any point in time, such that the tax revenue is totally devoted to reduce pollution. At location $x$ the tax revenue is $r(x, t)=\tau(x) s f[k(x, t)]$, while abatement activities, $a(x, t)$, decrease a certain share of pollution, $u(x) \in[0,1]$, by employing a certain amount of not consumed output with the following cost $a(x, t)=\mathcal{C}[u(x)] s f[k(x, t)]$, where $\mathcal{C}(\cdot)$ is the cost function $\left(\mathcal{C}^{\prime}>0, \mathcal{C}^{\prime \prime}>0\right)$ of abatement activities which are assumed to be convex and concave as in Kelly (2003). By equating the tax revenue and abatement we obtain that $\tau(x)=\mathcal{C}[u(x)]=1-[1-u(x)]^{\epsilon}$ with $\epsilon>1$, where the cost function is assumed to take the suitable form proposed by Bartz and Kelly (2008). Note that this specification is very convenient since it allows for a one-to-one relationship between the tax rate and the share of abated emissions: if $u(x)=0$ then $\tau(x)=0$ such that there is no pollution reduction and (not consumed) production is only allocated to capital accumulation; if $u(x)=1$ then $\tau(x)=1$ such that all generated emissions are abated and production is entirely devoted to reduce pollution.

Equation (2) illustrates the evolution of pollution. Production generates emissions which increase linearly the stock of pollution and $\theta$ measures the degree of environmental inefficiency of economic activities. As in Marsiglio (2015), these abatement activities reduce a share $u(x)$ of emissions, thus $1-u(x)$ represents unabated emissions. The integral term describes the idea that the emission flows at the position $x$ are due not only to the productive activities at the same spot $x$ but also to the productive activities in different localities, meaning that production at location $x^{\prime}, \forall x^{\prime} \in\left[x_{a}, x_{b}\right]$, does impact also on the emission flows faced by location $x$. Differently from the diffusion term embodied in Laplacian operator $\frac{\partial^{2}}{\partial x^{2}}$, the kernel $\varphi\left(x, x^{\prime}\right)$ does not describe how pollution spreads across space, but it is a purely static term characterizing proximity externalities not involving mobility; for example, these externalities may be generated by a pollutant that does not diffuse but nevertheless affect the neighbouring areas. In the extreme case we choose the Dirac's delta function as the kernel, the static externality effect would be eliminated (since the integral in the equation for $p$ then evaluates to $f[k(x, t)])$ and the above system would read as:

$$
\begin{aligned}
\frac{\partial k(x, t)}{\partial t} & =d_{k} \frac{\partial^{2} k(x, t)}{\partial x^{2}}+\frac{s(x) f[k(x, t)][1-u(x)]^{\epsilon}}{a+b[p(x, t)]^{2}}-\delta_{k} k(x, t) . \\
\frac{\partial p(x, t)}{\partial t} & =d_{p} \frac{\partial^{2} p(x, t)}{\partial x^{2}}+\theta[1-u(x)] f[k(x, t)]-\delta_{p} p(x, t) .
\end{aligned}
$$

With the simultaneous presence of diffusion and static externalities, our model can deal with a composite pollutant that presents both the characteristics connected to diffusion and static externalities. In both equations (1) and (2), the parameters $\delta_{k}$ and $\delta_{p}$ represent the depreciation rate of capital and pollution, respectively; similarly the parameters $d_{k}$ and $d_{p}$ measure the diffusion across space of capital and pollution, 
respectively. Specifically, $d_{k} \in[0,1]$ represents the hindrances which dampen spatial diffusion of capital, such as custom barriers, quantitative restrictions or any other government measure with the aim to contain the movements of capital and machines; the term $d_{p} \in[0,1]$ measures the natural tendency of pollution to spread across space, which to a large extent is out of the control of human beings.

For each fixed pair of savings rate and share of emission abated $(s, u)$, the above system of partial differential equations (1) - (2) admits a unique solution $\left(k^{c, u}, p^{c, u}\right)$. The steady state solution is a pair of smooth functions $\bar{k}^{c, u}, \bar{p}^{c, u} \in C^{2}\left(\left(x_{a}, x_{b}\right)\right) \cap C^{1}\left(\left[x_{a}, x_{b}\right]\right)$ which satisfy the following system:

$$
\begin{aligned}
0 & =d_{k} \frac{d^{2} k(x)}{d x^{2}}+\frac{s(x) f[k(x)][1-u(x)]^{\epsilon}}{a+b p(x)^{2}}-\delta_{k} k(x) . \\
0 & =d_{p} \frac{d^{2} p(x)}{d x^{2}}++\theta \int_{x_{a}}^{x_{b}}\left[1-u\left(x^{\prime}\right)\right] f\left[k\left(x^{\prime}, t\right)\right] \varphi\left(x^{\prime}, x\right) d x^{\prime}-\delta_{p} p(x) .
\end{aligned}
$$

Let us define $v=(k, p)$ and the following vector-valued function:

$$
F(v):=F(k, p)=\left[\begin{array}{c}
\frac{s f(k)[1-u]^{\epsilon}}{a+b p^{2}}-\delta_{k} k \\
\int_{x_{a}}^{x_{b}} f(k) \varphi d x^{\prime}-\delta_{p} p
\end{array}\right]
$$

The model (1) - 2) can be rewritten in vectorial form as an ordinary differential equation in a suitable Banach space as follows:

$$
\frac{d v}{d t}=D \Delta v+F(v)
$$

where $D=\operatorname{diag}\left(d_{i}\right)$ is a diagonal matrix and $\Delta$ corresponds to the second order derivative with respect to the spatial variable. Denote by $W$ the real Banach space $C([a, b])$ of continuous vector-valued functions $v:[a, b] \rightarrow \mathbb{R}^{2}$ endowed with the usual norm $\|v\|=\sum_{i} \sup _{x \in[a, b]}\left|v_{i}(x)\right|$. The problem (1) - 2) defines a local semiflow $\Psi$ on the Banach space $W$. For any $v_{0}=\left(k_{0}, p_{0}\right) \in W, \Psi\left(t ; v_{0}\right)$ provides the unique solution of the problem (1) - (2) and it satisfies both the maximality and the compactness property (see Mora, 1983). Moreover, it is also possible to prove that the solutions $k(x, t)$ and $p(x, t)$ satisfy:

$$
k(x, t) \geq 0, p(x, t) \geq 0 \text {, and } p(x, t) \text { is bounded from above, } x \in\left[x_{a}, x_{b}\right], t \geq 0 .
$$

\section{Spatio-Temporal Dynamics}

It is well known that systems similar to ours cannot be solved analytically (with the exception of the linear production function case, as in Boucekkine et al., 2013b). Thus, in order to analyze the behavior of capital and pollution we need to rely on numerical simulations. In the following we consider two different specifications of the production function: a globally concave Cobb-Douglas production function which represents the natural benchmark for our analysis, and a convex-concave production technology, as in Anita et al. (2013). This is introduced in order to allow for the possibility of poverty traps and compare how the outcomes may differ from the canonical Cobb-Douglas case. Such a convex-concave specification rely on Skiba's (1978) argument that decreasing marginal returns can describe only developed economies, while for less developed countries capital may need first to exceed a certain threshold in order for decreasing marginal returns to settle in.

\subsection{Concave Production: the Benchmark Case}

Consider first a neoclassical, globally concave, Cobb-Douglas production function:

$$
f[k(x, t)]=A k(x, t)^{q}, q<1,
$$


where $A$ is a productivity parameter and $q<1$ denotes the capital share. In this case, the semiflow $\Psi$ is monotone and concave, guaranteeing the convergence to a nontrivial steady state. To visualize the long-run behavior of the system (1) - (2), we perform a numerical simulation, with the following parameter values and initial conditions:

$$
\left\{\begin{array}{l}
s(x)=0.2, u(x)=0.5, \theta=0.02, \epsilon=1.5, x_{a}=-1, x_{b}=1, \\
\delta_{k}=0.05, \delta_{p}=0.05, a=1, b=0.01 \\
k_{h}=0.86, p_{h}=0.86, d_{h}=0.1, \sigma_{h}^{2}=0.06 \\
k_{l}=0.22, p_{l}=0.22, d_{l}=0.001, \sigma_{l}^{2}=0.5 \\
A=100, q=0.33, d_{k}=d_{p}=d_{h}, \\
k(x, 0)=k(x, 0)_{h}=k_{h} e^{-\frac{x^{2}}{\sigma_{h}^{2}}}, p(x, 0)=p(x, 0)_{h}=p_{h} e^{-\frac{x^{2}}{\sigma_{h}^{2}}} \\
\varphi\left(x^{\prime} x\right)=\frac{1}{\sqrt{2 \pi} \varepsilon} e^{-\frac{\left(x-x^{\prime}\right)^{2}}{2 \varepsilon^{2}}}, \text { with } \varepsilon=\frac{1}{\sqrt{2 \pi}}
\end{array}\right.
$$

In Section 4 we will let the saving rate and share of abated emissions be endogenously determined, but for the time being we simply assume they are constant over time but non-homogeneous across space. We firstly allow the saving rate, $s$, to be constant at any location, namely we set $s(x, t)=0.2$ which represents a standard value for Solow-type models (in a spatial growth context, see Camacho and Zou, 2004). The depreciation rate of capital and the capital share, $\delta_{k}=0.05$ and $q=0.33$ respectively, are consistent with most of the growth literature (see Barro and Sala-i-Martin, 2004). The pollution decay rate, $\delta_{p}$ is set equal to 0.05 (see, for example Saltari e Travaglini, 2014). The share of abated emission, $u(x, t)$, is constant at its average value, $u(x, t)=0.5$. The cost parameter, $\epsilon$, is set equal to 2 for the sake of simplicity: different choices of $\epsilon$ around such a value do not change our conclusions. The diffusion coefficients, $d_{k}$ and $d_{p}$, are set arbitrarily to allow the diffusion to clearly affect the economic and environmental outcomes, permitting thus to appreciate the consequences of this force on capital and pollution; specifically, we will consider high and low diffusion coefficients, $d_{h}$ and $d_{l}$ respectively. The initial distribution of capital and pollution, $k(x, 0)$ and $p(x, 0)$, are chosen to mimic an initial non-homogeneous distribution of $k$ and $p$. The auxiliary parameters $k_{h}, k_{l}, p_{h}, p_{l}, \sigma_{h}^{2}$ and $\sigma_{l}^{2}$, shape the initial profile of capital and pollution, and are set to simplify the comparisons between the different scenarios in the remainder of the paper. The environmental production inefficiency, $\theta$, the total factor productivity, $A$, and the two damage function parameters, $a$ and $b$, are set in such a way to improve the readability of our (graphical) results, that is to facilitate an immediate grasp of the main ideas just by a glance at the figures: their numerical values do not affect any of our qualitative results.

It is worth to comment on the specification of the kernel function $\varphi\left(x^{\prime}, x\right)$. If our spatial domain was infinite, the function $\varphi\left(x^{\prime}, x\right)$ would possess the following property: $\int_{-\infty}^{+\infty} \varphi\left(x^{\prime}, x\right) d x^{\prime}=1$. That would be interesting because we could think about the Dirac's delta function as the limit distribution of our kernel function. This point of view could then help us to interpret our integro partial differential system as a natural generalization of a standard reaction diffusion system. Our domain is actually finite and the specified kernel function introduces some asymmetries. In particular the closer the position $x$ is to the left (right) boundary $x_{a}\left(x_{b}\right)$, the more truncated is the left (right) tail of the kernel function, and the less contribution the integral provides to the pollution faced at the point $x$. Hence the central regions around $x=0$ are the most affected by the static spatial externalities. In other words, the specified kernel function is chosen to allow the Dirac's delta function to be its limit distribution, and to create an externality with spatial heterogeneity effects, as we will see.

The evolution of both capital and pollution are illustrated in Figure 1. Intuitively in our benchmark Cobb-Douglas case, since the production function is concave, the economy does not have to face take off problems $3^{3}$ and therefore as time elapses, both capital and pollution reach their positive steady state levels. Therefore, the economy develops along a sustainable path: capital and pollution first have dynamics and

\footnotetext{
${ }^{3}$ See Skiba (1978) and Sachs et al. (2004) for a critical discussion of the assumption of decreasing marginal returns, embedded
} 

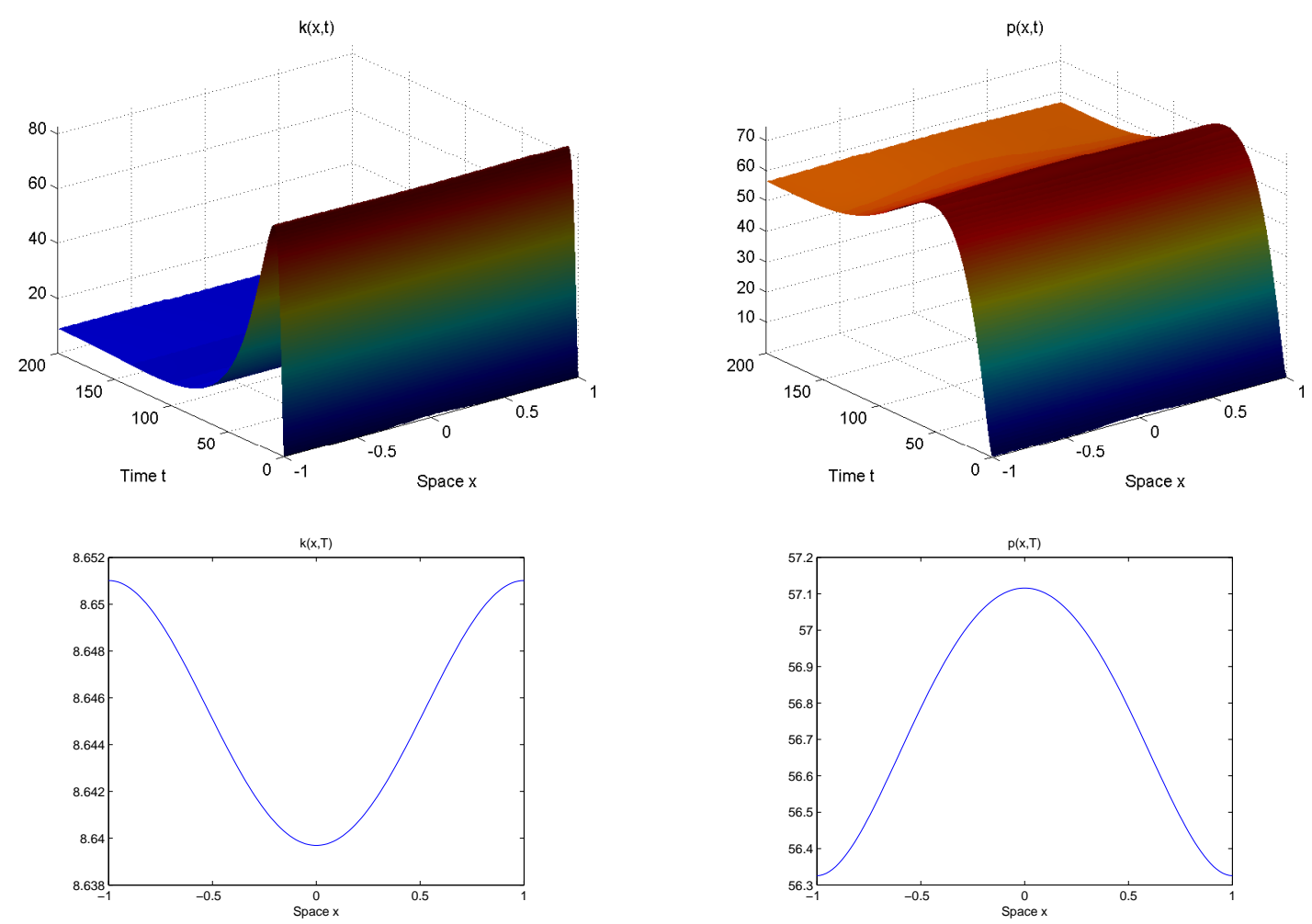

Figure 1: Cobb-Douglas production case: evolution of capital and pollution $\left(d_{k}=d_{p}=d_{h}\right.$ and $k(x, 0)=$ $\left.k(x, 0)_{h}\right)$

then stabilize at their positive long run level. Note that the long run steady state is non-homogeneous across space; to understand such an outcome we need to consider the two opposite forces acting on the spatial distribution of capital and pollution. On the one hand, diffusion is a convergence mechanism, that is diffusion tends to smooth the spatial differences out, translating the idea of decreasing returns to capital: capital moves toward regions where the returns are higher, that is regions in which capital is scarce. If there are no spatial exogeneous differences either in the production function or in the saving rate or in the abatement share, namely if $f, s$ and $u$ do not explicitly depend on $x$, this smoothing out process continues until the initial space dependent profiles $k(x, 0)$ and $p(x, 0)$ fade away (see Brito, 2004, Camacho and Zou 2004). On the other hand, the integral term represents a divergence mechanism: it introduces (static) nondiffusive spatial externalities at location $x$, being the positions around $x=0$ the most affected venues by the amount of pollution available in the overall economy. We can think about such non-diffusive contributions as the effect of that part of the stock of pollution that is really hard to move, such that it cannot diffuse but still affects the areas surrounding the production site. Looking at the steady state profiles of capital and pollution, at the bottom panels of Figure 1, it is possible to conclude that overall the strength of the diffusive force is not enough to completely overcome the effect of the spatial externality. The regions with the highest levels of steady state pollution are the central ones, since the integral-induced effect is stronger. As a consequence, given the role of the damage function, these are even the regions where less capital is accumulated in the long run. In order to more easily visualize the divergence role of the kernel integral we repeat the above simulation with the same parameter values, except for the absence of integral term, that

in a concave production function. They claim that such a formulation can be considered an accurate description only of developed economies, but cannot be applied to less developed economies, often facing poverty traps; for this reason Skiba (1978) suggests that convex-concave production functions can better describe real world economies. 

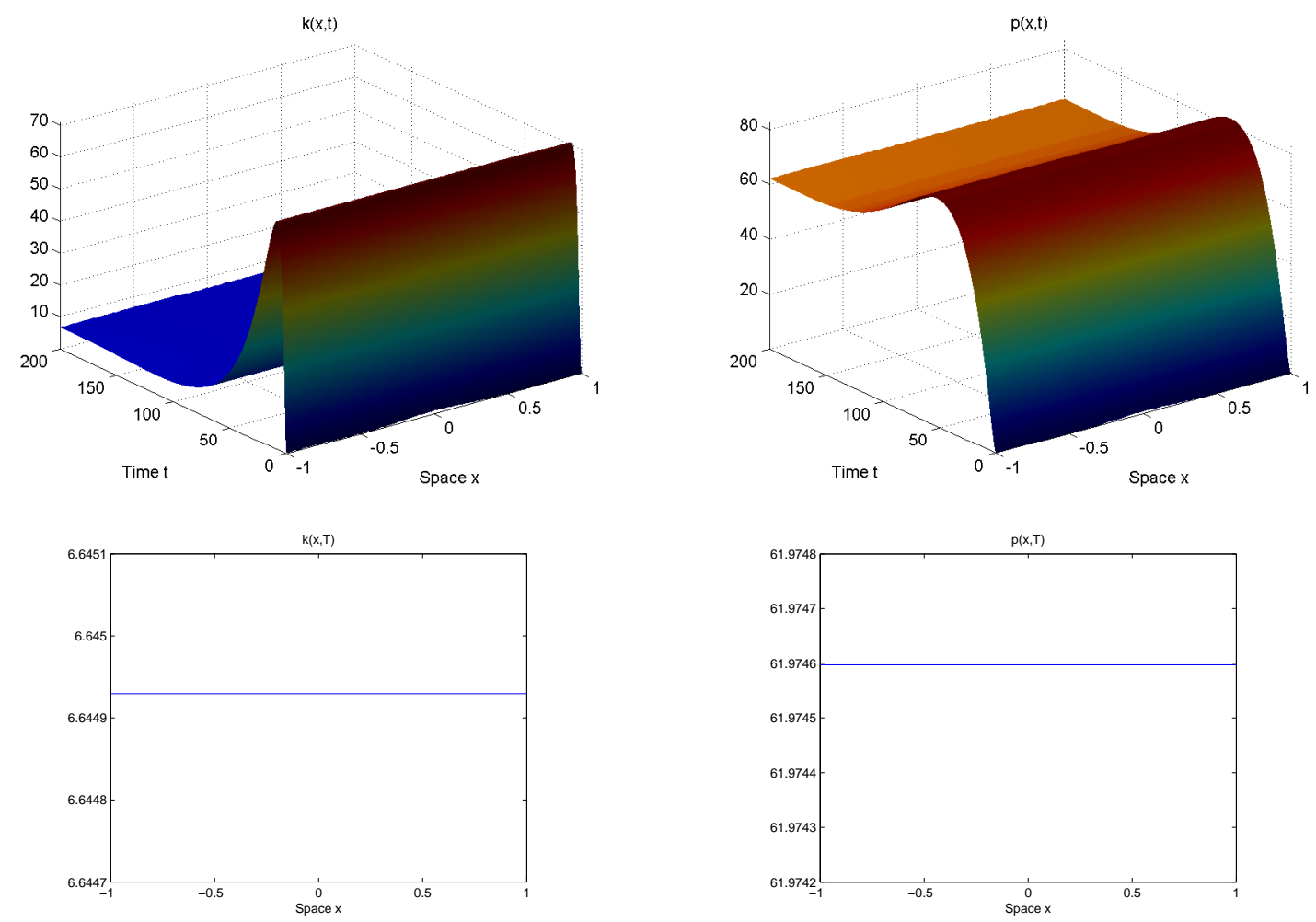

Figure 2: Cobb-Douglas production case: evolution of capital and pollution (with $d_{1}=d_{2}=1$ and $k_{0}=1$, along with $\phi(x)=\delta(x))$.

is we set $\phi(x)=\delta(x)$. The system becomes:

$$
\begin{aligned}
& \frac{\partial k(x, t)}{\partial t}=d_{1} \frac{\partial^{2} k(x, t)}{\partial x^{2}}+\frac{s(x) f[k(x, t)][1-u(x, t)]^{\epsilon}}{a+b p(x, t)^{2}}-\delta_{k} k(x, t) . \\
& \frac{\partial p(x, t)}{\partial t}=d_{2} \frac{\partial^{2} p(x, t)}{\partial x^{2}}+\theta[1-u(x, t)] f[k(x, t)]-\delta_{p} p(x, t) .
\end{aligned}
$$

As we can see in Figure 2, capital and pollution reach a spatially homogeneous steady state, given that now diffusion is the only force taking place. Thus, by comparing the bottom part of Figure 1 and Figure 2 it is possible to appreciate the contribution of the non-diffusive spatial externalities (i.e., the integral term) in the fully fledged model. Non-diffusive spatial externalities by introducing some spatial heterogeneity in the evolution of pollution allow some spatial heterogeneity to persist in the long run level of both capital and pollution.

\subsection{Convex-Concave Production and Poverty Traps}

In order to enrich both the economic and environmental dynamics and consider the eventual presence and effects of poverty traps on the accumulation and diffusion of capital and pollution over time and across space, we now focus on a convex-concave production function as suggested in Skiba (1978). For the sake of simplicity, as in Anita et al. (2013) we consider the following functional form:

$$
f[k(x, t)]=\frac{\alpha_{1} k(x, t)^{q}}{1+\alpha_{2} k(x, t)^{q}}, q>1,
$$

where $\alpha_{1}$ is a productivity parameter, and $\alpha_{2}$ measures eventual diseconomies 4 . Because the production function is S-shaped, the analysis of the model is complicated due to lack of concavity of the evolution oper-

\footnotetext{
${ }^{4}$ Even if it can be discussed whether this specific formulation of a convex-concave production is relevant or can be empirically supported, there are no doubts on the fact that the standard neoclassical globally concave production function is overly simple
} 
ator; some analytical results about local stability of steady states can be found in Capasso and Maddalena (1982). Capasso et. al. (2010) analyze a spatial Solow model under a similar non-concave production function showing the existence of three equilibria, where two are stable and one is unstable, with the unstable equilibrium corresponding to the poverty trap threshold, as discussed in Skiba (1978).

By assuming such a specification for the production function our model might give rise to similar poverty trap outcomes. Before looking more in depth to what this implies for our economic and environmental framework, we need to carefully understand what a poverty trap might represent in our spatial framework. In Skiba's (1978) seminal work, since a space structure is completely missing the poverty trap threshold is the initial capital level, say $k_{t h}$, that separates the basins of attraction of the lower and the upper stable equilibria: if the economy starts below this threshold, $k_{0}<k_{t h}$, the system evolves towards the lower equilibrium $k_{l}$, while the upper equilibrium $k_{u}$ is eventually reached if the initial capital is above $k_{t h}$, i.e. $k_{0}>k_{t h}$; basically, $k_{t h}$ is a point in the capital domain representing the unstable equilibrium of the economy. The introduction of a space structure like ours complicates dramatically the analysis. Indeed, since we are dealing with an infinite dimensional problem, the equivalent notion of poverty trap threshold is a $\mathcal{C}^{2}$-function, representing the unstable (middle) equilibrium of the system: if the initial distribution of capital were exactly equal to this threshold function $k_{0}(x)=k_{t h}(x)$, the system would not evolve at all. All the other initial distributions of capital are attracted either to the low or to the high equilibrium, but it is not possible to order them with an inequality sign, as in the one dimensional case, because there is no such an ordering in the space of functions. Nevertheless, in the absence of diffusion, it is possible to define a "spatial poverty trap threshold" function: this spatial threshold will help us to appreciate the effects of diffusion in a number of scenarios. In order to understand what this spatial threshold function may represent, let us neutralize for a while both the diffusion (by setting $d_{k}=d_{p}=0$ ) and all the spatial exogenous heterogeneities (setting both the saving rate and the share of abated emission equal to some constant value, $s(x)=s$ and $u(x)=u$, and the kernel function equal to the Dirac's delta function, $\phi(x)=\delta(x)$ ), apart from those due to the initial capital and pollution distribution (letting $k(x, 0)=k_{0}(x)$ and $p(x, 0)=p_{0}(x)$ ); this implies that the space variable $x$ in our system is now de facto a parameter. The system of partial differential equations (1) - (2) boils down to the following parametric system of ordinary differential equations, which at each point $x$ can be solved along with the initial conditions $k(x, 0)=k(x)$ and $p(x, 0)=p(x)$ :

$$
\begin{aligned}
\frac{d k_{x}(t)}{d t} & =\frac{s f\left[k_{x}(t)\right][1-u]^{\epsilon}}{a+b p_{x}(t)^{2}}-\delta_{k} k_{x}(t) . \\
\frac{d p_{x}(t)}{d t} & =\theta[1-u] f\left[k_{x}(t)\right]-\delta_{p} p_{x}(t) .
\end{aligned}
$$

The above system has clearly three equilibria, two stable and one unstable. The unstable equilibrium $k_{t h}$ is the poverty trap threshold, exactly as in Skiba's (1978) framework. Now we can define $k(x)=k_{t h}$ as our spatial poverty trap threshold, that is a function representing what the poverty trap threshold might be in a framework with no diffusion.

to give rise to realistic results. The formulation we present here maintains very useful tractable properties and allows for the existence of poverty traps. In particular, if $q>1$, it satisfies most of the neoclassical properties, since it shows constant returns to scale, positive and diminishing (only for higher capital levels) marginal returns which converge to zero as capital gets larger and larger. If $q \leq 1$, instead the production function results to be concave, and the results will not be qualitatively different from the Cobb-Douglas case. For this reason we consider such a type of production function to be a better benchmark for investigating real world problems. 
For the simulation $5^{5}$ in this section, the values of the parameters and initial conditions are the following:

$$
\left\{\begin{array}{l}
s(x)=0.2, u(x)=0.5, \theta=0.02, \epsilon=1.5, x_{a}=-1, x_{b}=1, \\
\delta_{k}=0.05, \delta_{p}=0.05, a=1, b=0.01, \alpha_{1}=1, \alpha_{2}=1, \\
k_{h}=0.86, p_{h}=0.86, d_{h}=0.1, \sigma_{h}^{2}=0.06 \\
k_{l}=0.22, p_{l}=0.22, d_{l}=0.001, \sigma_{l}^{2}=0.5, \\
A=100, q=4, d_{k}=d_{p}=d_{h} \text { or } d_{l}, \\
k(x, 0)=k(x, 0)_{h}=k_{h} e^{-\frac{x^{2}}{\sigma_{h}^{2}}}, p(x, 0)=p(x, 0)_{h}=p_{h} e^{-\frac{x^{2}}{\sigma_{h}^{2}}} \text { or } \\
k(x, 0)=k(x, 0)_{l}=k_{l} e^{-\frac{x^{2}}{\sigma_{l}^{2}}}, p(x, 0)=p(x, 0)_{l}=p_{l} e^{-\frac{x^{2}}{\sigma_{l}^{2}}}, \\
\varphi\left(x^{\prime} x\right)=\frac{1}{\sqrt{2 \pi} \varepsilon} e^{-\frac{\left(x-x^{\prime}\right)^{2}}{2 \varepsilon^{2}}}, \text { with } \varepsilon=\frac{1}{\sqrt{2 \pi}} .
\end{array}\right.
$$

In Figure 3 we compare two initial capital distributions (we do leave pollution aside for the time being), their dynamics and their long run behavior, in the absence of diffusion. In the top panels the red dotted line represents the spatial threshold introduced abov ${ }^{6}$, we can see that the share of rich (i.e., those lying above the threshold) and poor (i.e., those lying below the threshold) regions is the same in the two scenarios, while the initial spatial distribution of capital is clearly different (in the left panel rich regions are relatively much richer than poor regions, while in the right panel rich and poor regions do not show such a strong difference in their initial capital endowments). In the absence of capital diffusion the only thing that matters for the dynamic evolution of the economy is the initial capital level, thus it turns out that the two scenarios have similar dynamics (middle panels), and identical long run spatial profiles (bottom panels): rich regions converge towards the high equilibrium, while poor regions are trapped in the low (zero capital) equilibrium.

In Figure 4 diffusion steps in and the two scenarios have no longer the same dynamics and long run outcome: in the left panels, where the rich regions have a more abundant endowment of capital, the diffusioninduced effect is beneficial and even poor regions are able to reach the high equilibrium. However, diffusion is not beneficial a priori, as we can see from the right panels of the same Figure: if the capital endowment of the rich regions is not sufficiently large, diffusion could even bring every region, both rich and poor regions, to collapse. What this result suggests is that the initial capital distribution plays a fundamental role in determining whether the convergence mechanism triggered by diffusion might have overall a positive or negative effect on the whole spatial economy; in particular, if rich regions are particularly rich diffusion can help poor regions to escape the poverty trap. In economic terms, this means that in a spatial economy with heterogeneous capital endowments, whenever rich regions are rich enough the spatial economy might have internally the resources required to provide poor regions with the big push they need to escape poverty (Sachs et al., 2004); whenever rich regions are not rich enough the spatial economy might fail in the attempt to help poor regions and as a result also rich regions will be pulled into poverty.

In this discussion about the strength of diffusion in shaping the dynamics of the spatial economy, we have not considered the effects of pollution yet. However, pollution crucially affects the dynamics of capital through two terms: the degree of environmental inefficiency of economic activities (the parameter $\theta$ ) and the damage function (the parameters $a$ and $b$ ); if any of these terms increases, the spatial threshold rises too while the high equilibrium level of capital falls, making escaping the poverty trap more difficult and at the same time the long run outcome less satisfactory. We can observe such an outcome in Figure 5, where both the economy on the left and right panels share the same initial capital endowments as the economy on the left panels of the previous Figure 4 (that is, rich regions are substantially rich), but they are characterized

\footnotetext{
${ }^{5}$ In the following simulations we set arbitrarily $q=4$, since the qualitative results are equivalent for any other value of $q$ such that $q>1$, which represents the relevant case for generating an S-shaped production function, according to 5 .

${ }^{6}$ In this paper, as a matter of expositional simplicity, we refer to the set of locations lying above the spatial threshold as "rich regions" and the set of those lying below the spatial threshold as "poor regions". Note that also within the group of rich and poor regions there exists a certain degree of heterogeneity in the initial distribution of capital, what we we will be referring to as "spatial capital distribution".
} 

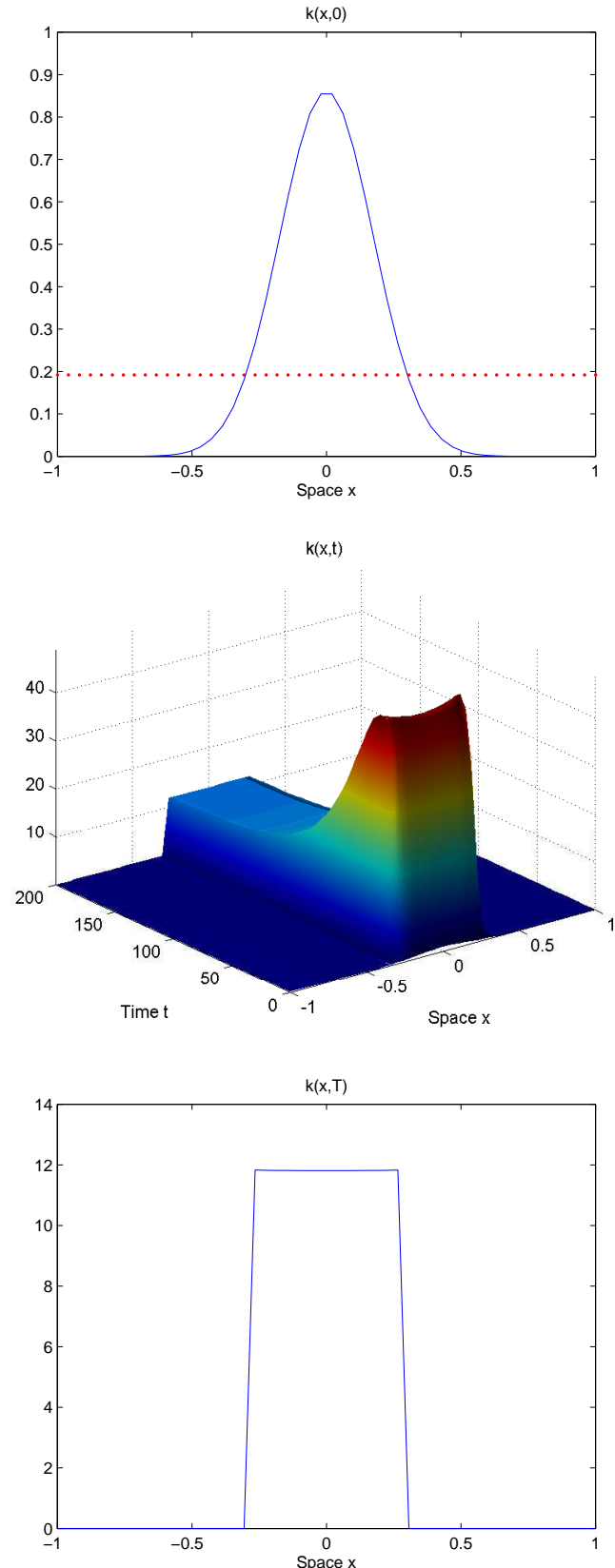
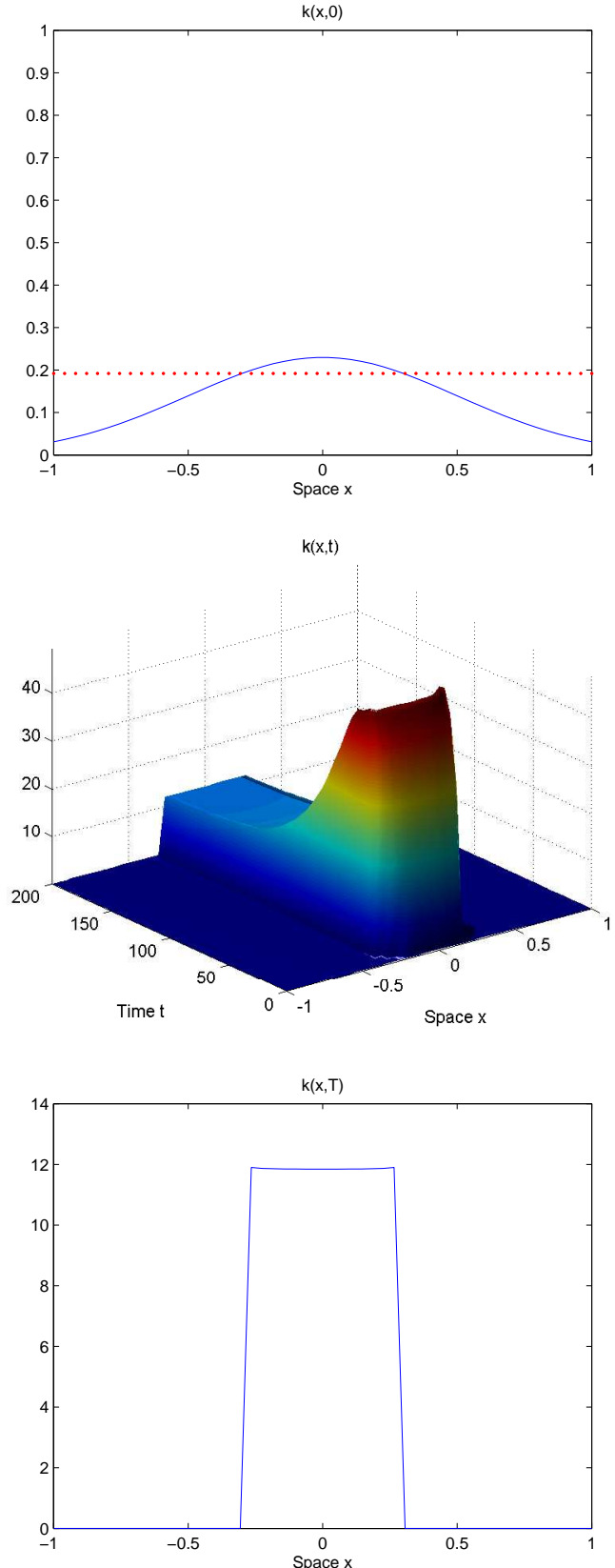

Figure 3: S-shaped production case: initial capital allocation for $k(x, 0)=k(x, 0)_{h}$ (left panel), and $k(x, 0)=$ $k(x, 0)_{l}$ (right panel),spatial poverty trap threshold and evolution of capital and pollution (no diffusion).

by different values of $b$ and $\theta$ (we increase $b$ in the economy on the left, and we increase $\theta$ in the economy on the right). The dynamics are slightly different but the long run behavior of the economies is the same: long run collapse. We can note that the two parameters affect the dynamics of capital in a very different way: when $b$ increases the rich regions in which also the initial pollution is high, immediately experience the stronger negative effects associated with the pollution externality losing their capital advantage, while when $\theta$ increases the rich regions keep their initial capital advantage on poor regions for some time. This highlights that the damage function (by affecting the capital dynamic equation) affects the economy even in the short run and its implication on the spatial distribution of capital can be detected soon, while the degree of environmental inefficiency (by affecting capital dynamics only indirectly through the pollution dynamic equation) has only long run effects, even though they are similarly negative. By comparing Figure 5 and Figure 4 we can note that not only the initial capital distribution matters for determining whether the spatial 

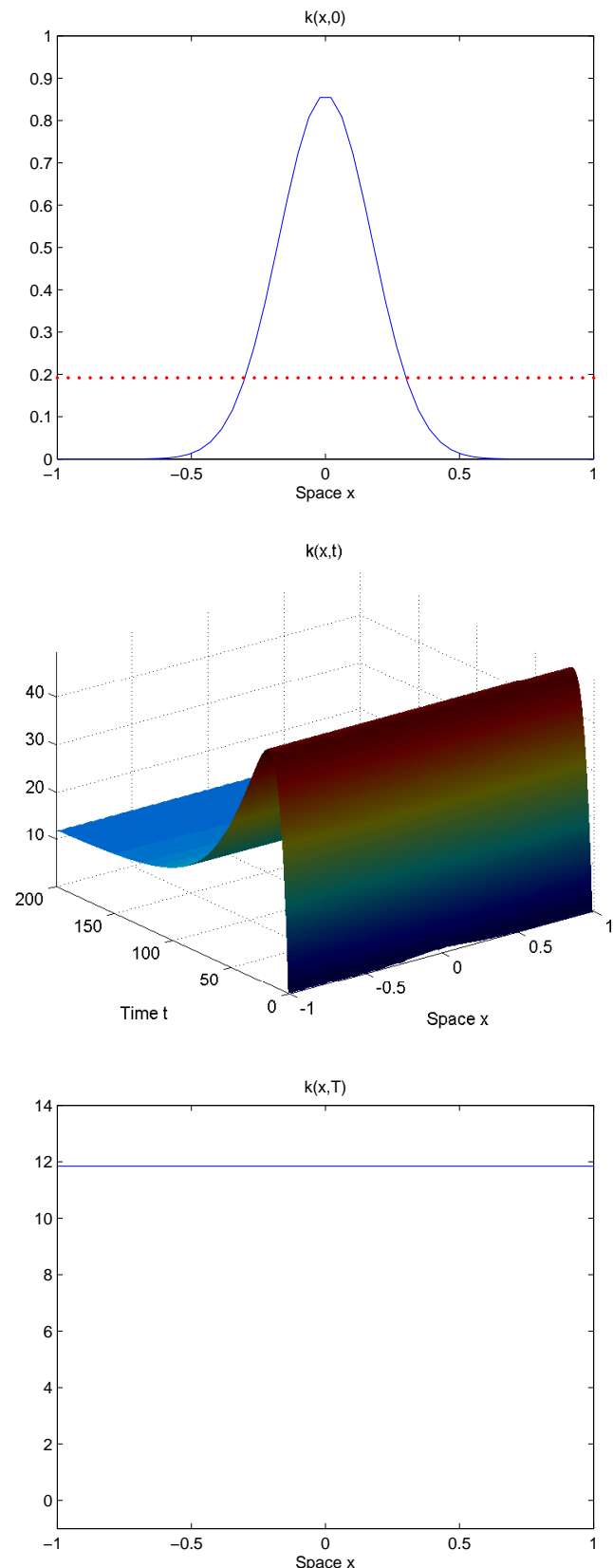
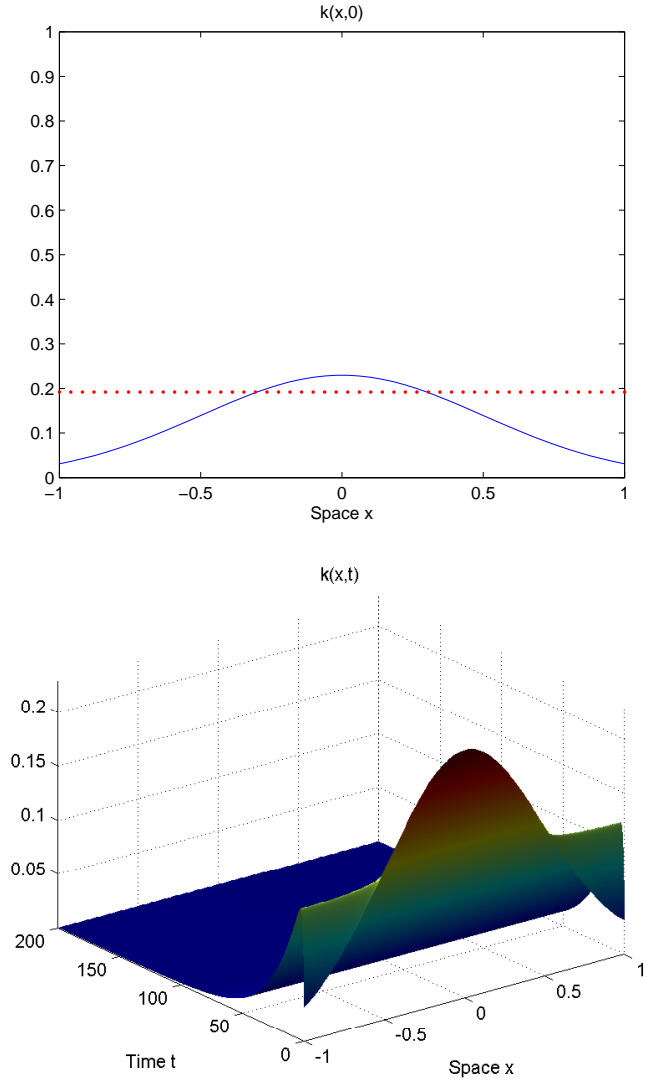

$k(x, T)$

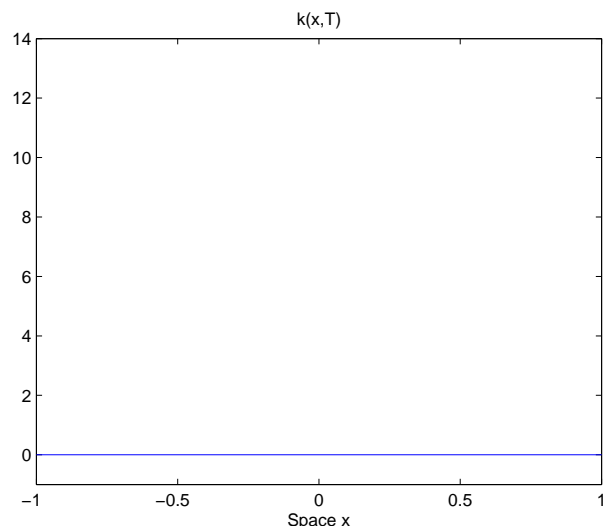

Figure 4: S-shaped production case: initial capital allocation for $k(x, 0)=k(x, 0)_{h}$ (left panel), and $k(x, 0)=$ $k(x, 0)_{l}$ (right panel), spatial poverty trap threshold and evolution of capital and pollution (with diffusion).

economy will be able to to converge to the high capital equilibrium level or not, but also the pollution-induced effect does. Indeed, if pollution strongly affects output (directly through the damage function, or indirectly through the degree of environmental inefficiency) even if rich regions are substantially rich the whole spatial economy might be condemned to collapse in the long run.

We now turn back to the fully fledged model and we explore the behavior of (1) - (2), subject to (5). We consider different values for $d$ and $k(x, 0)$ in order to illustrate the effect of the diffusion and the initial capital distribution on the long run outcome of the spatial economy. In particular, we use the values $d=d_{h}$ and $d=d_{l}$, which correspond to high diffusion and low diffusion, respectively, for both capital and pollution. We alternatively chose $k(x, 0)=k(x, 0)_{h}$ or $k(x, 0)=k(x, 0)_{l}$, as in the upper panels of Figure 4. As in the previous discussion, the share or rich and poor regions are the same in the different scenarios. The goal of the simulations illustrated from Figure 6 to Figure 9 is to show the combined effects of diffusion and initial 

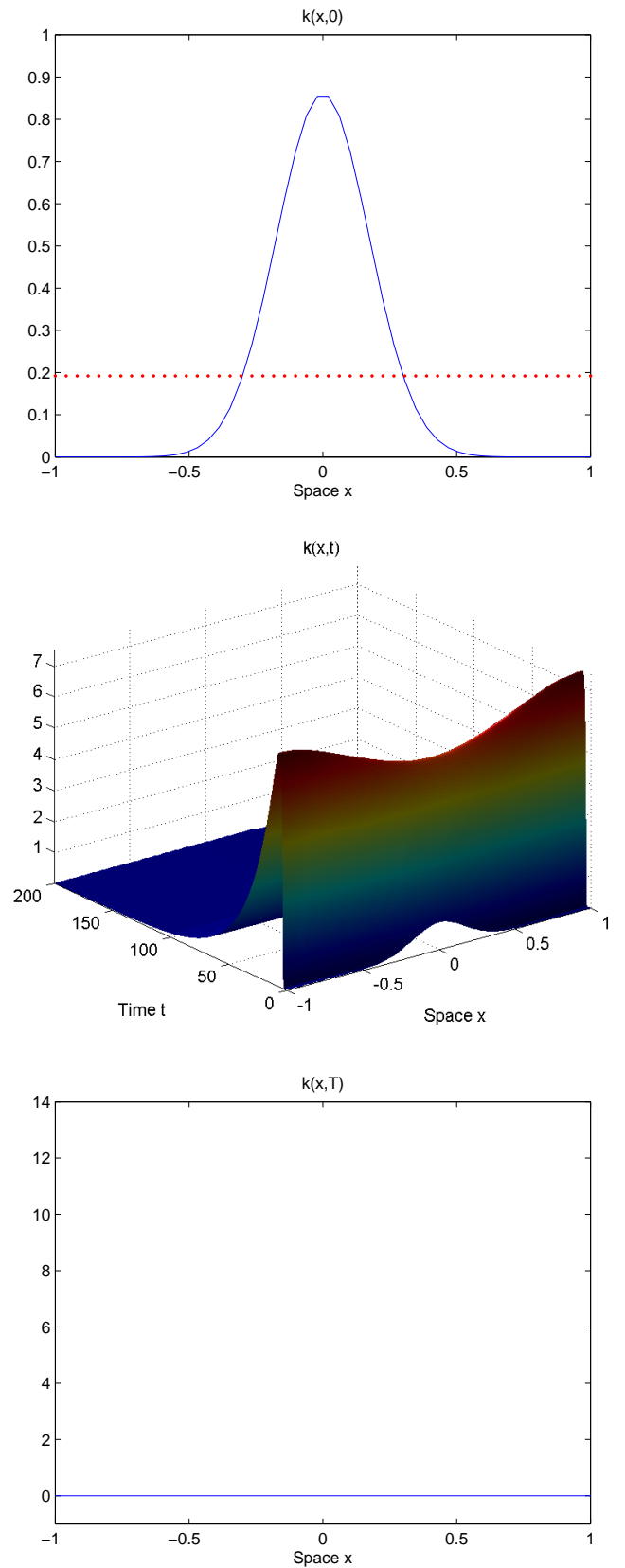
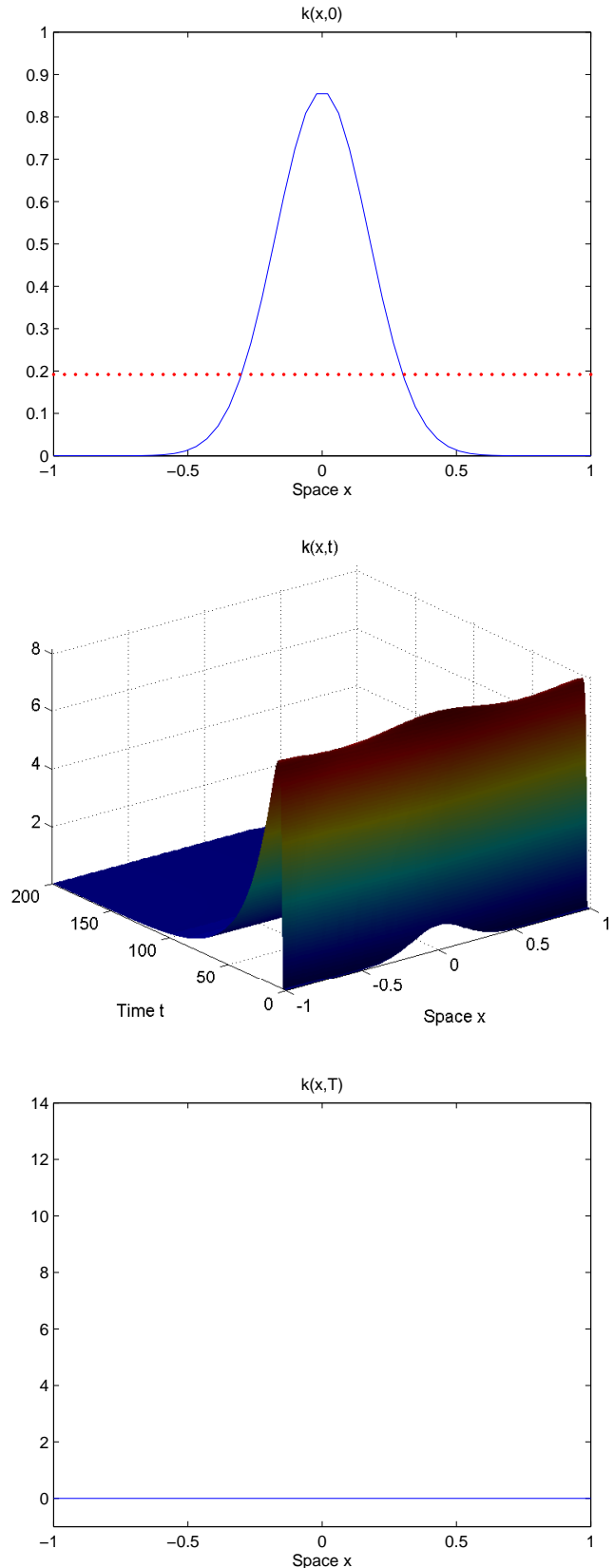

Figure 5: S-shaped production case: initial capital allocation for $k(x, 0)=k(x, 0)_{h}$ with higher $b$ (left panel), and $k(x, 0)=k(x, 0)_{h}$ with higher $\theta$ (right panel), spatial poverty trap threshold and evolution of capital and pollution (with diffusion and changes in pollution effects).

capital distribution on the long run economic and environmental outcome. Figure 6 presents the steady state solutions and the solutions surfaces in the case in which $d=d_{h}$ and $k(x, 0)=k(x, 0)_{h}$. Both $k$ and $p$ approach non-trivial steady states. The economy evolves along a sustainable path along which capital and pollution experience dynamics before reaching their steady states eventually. By observing the final time profile of $k$ and $p$ it is possible to note that a long run heterogeneity in space survives, even if the value of the diffusion coefficient is high. Comparing Figure 1] with Figure 6, whose simulations rely on the same set of parameters and functions apart from the production function, and considering that the relative peak-bottom distance in their respective final time profiles is almost exactly the same in the two cases, we can conclude that what really matters in generating a spatial heterogeneity is the externality embedded in the kernel function, as previously shown for the Cobb-Douglas case. This is a noticeable result because it 

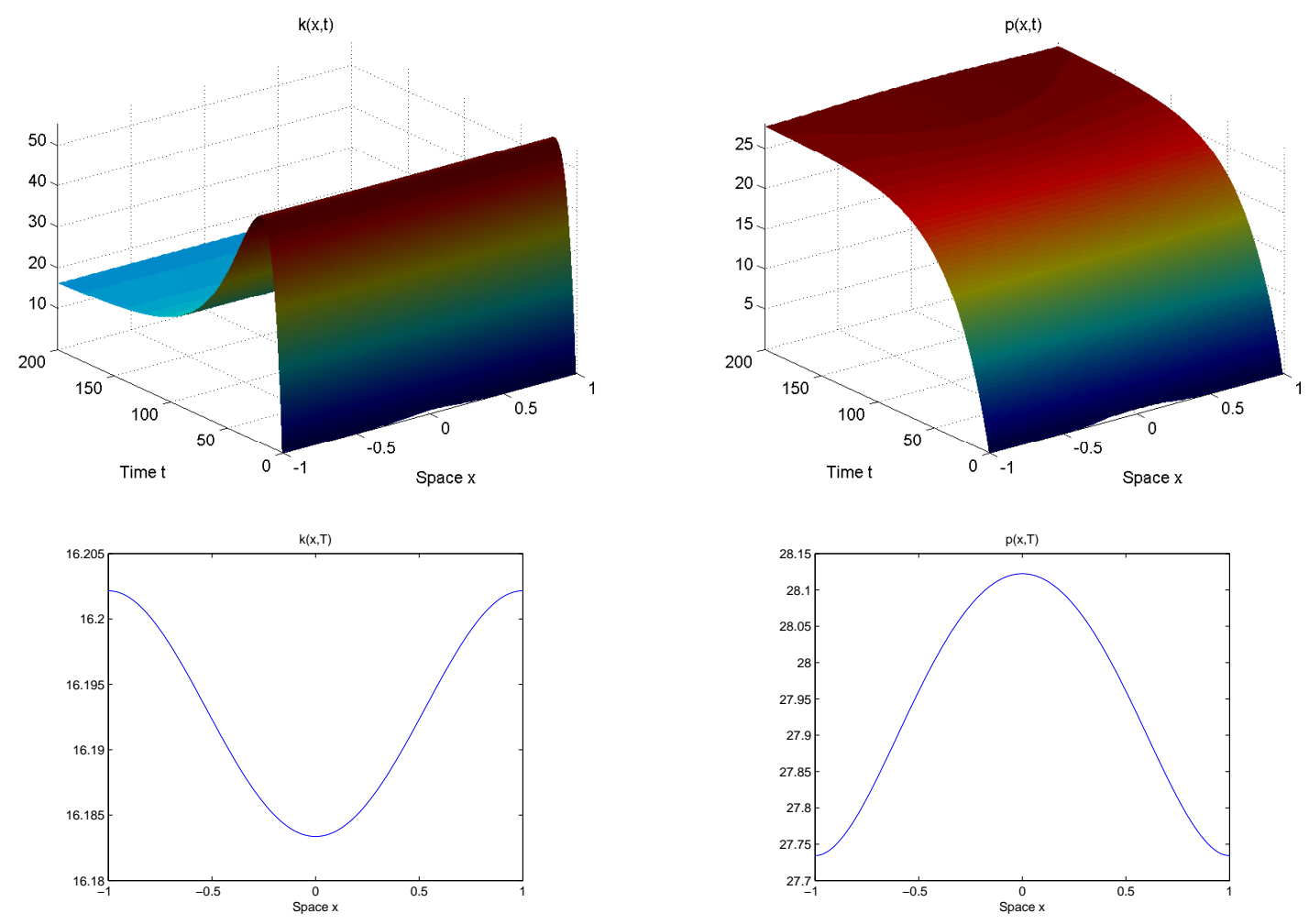

Figure 6: S-shaped production case: evolution of capital and pollution (with $k(x, 0)=k(x, 0)_{h}$ and $d=d_{h}$ ).

shows how the effect of non-diffusive pollution externalities shape the long run spatial profile of the economy: rich regions enjoy a sustainable path, but their long run achievements are negatively affected by the grater amount of pollution they eventually suffer. However, even if the diffusion (that is the possibility for capital and pollution to freely flow across regions) does not overcome the exogenous asymmetries introduced by the kernel function, it turns out to have overall a positive effect. Indeed, since the initial capital endowment in rich regions is sufficiently abundant, this permits also poor regions to achieve a sustainable steady state. Next, we reduce the level of capital and pollution diffusion by setting $d=d_{l}$. Figure 7 shows that both $k$ and $p$ reach non-trivial, non-homogeneous steady states in this scenario. The spatial heterogeneity is now considerably sharper than before, but nevertheless the initial capital endowment guarantees a sustainable steady state for all the regions in the domain.

Then we reduce the overall initial capital by setting $k(x, 0)=k(x, 0)_{l}$. When $d=d_{h}$, the capital and pollution diffusion levels are high enough to ensure that all regions suffer. Figure 8 confirms that in such a case the resulting solutions for both $k$ and $p$ approach zero. Even if in the initial spatial distribution of capital there are some rich regions, diffusion drains away resources so heavily that eventually all the regions, both rich and poor, are doomed to the same dire destiny. Differently from the previous case, where diffusion is actually helping poor regions to escape their poverty trap, here the possibility for capital to freely flow toward underdeveloped regions is quite negative ruling out the possibility of achieving a sustainable path for all the regions in the domain. Note that, as discussed earlier, the initial capital distribution is crucial in this respect.

Not only the initial capital distribution matters but also the intensity of the diffusion parameter does. In fact, if the diffusion terms are smaller, as set equal to $d=d_{l}$ as in Figure 9 , both $k$ and $p$ reach a non-trivial, non-homogeneous steady state (exactly the same steady state as in Figure 7, being the initial value of $k$ the only difference between the two simulations). Slowing down the diffusion of capital helps every region to grow along a sustainable path. When $k(x, 0)=k(x, 0)_{l}$, a variation of the diffusion coefficient from 
$k(x, t)$
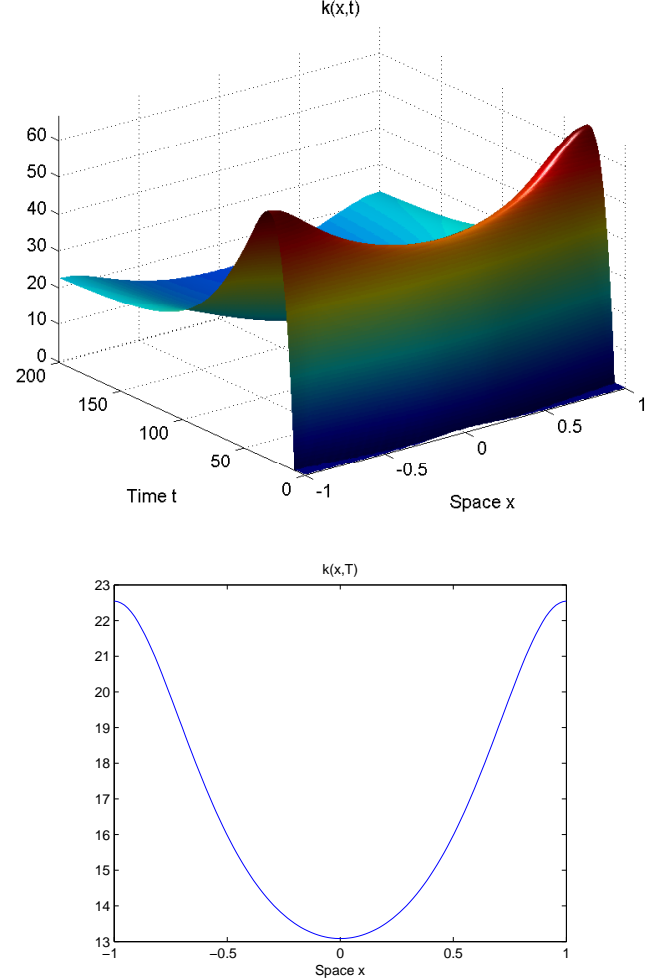

$p(x, t)$
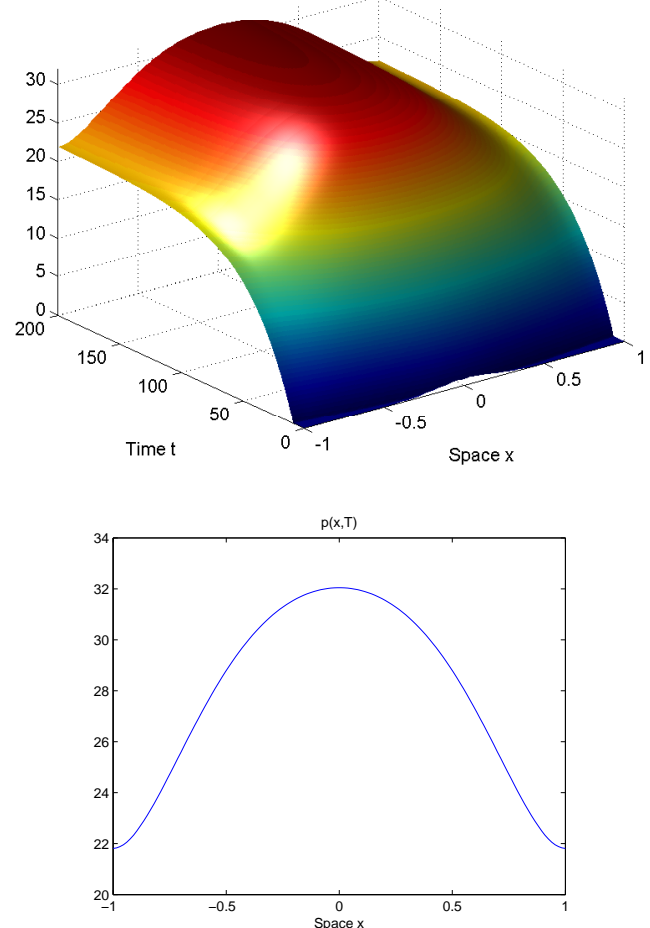

Figure 7: S-shaped production case: evolution of capital and pollution (with $k(x, 0)=k(x, 0)_{h}$ and $d=d_{l}$ ).
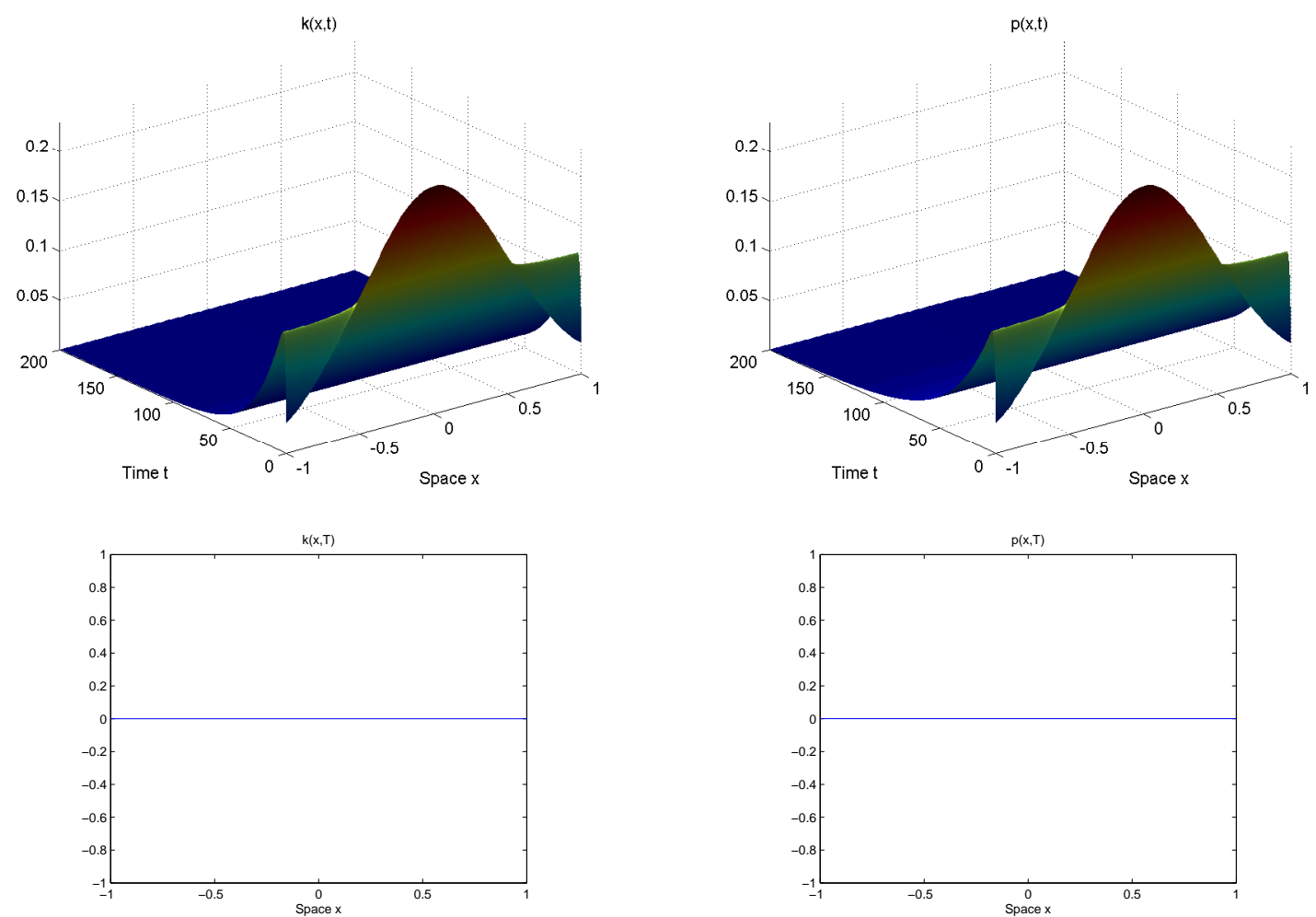

Figure 8: S-shaped production case: evolution of capital and pollution (with $k(x, 0)=k(x, 0)_{l}$ and $d=d_{h}$ ).

$d=d_{l}$ to $d=d_{h}$ is devastating, leading every region in the spatial economy to collapse to a zero capital level. In other words, reducing the diffusion can be beneficial for some initial capital distributions: indeed, 
while before the reduction of the diffusion, the initial capital distribution of the spatial economy belongs to the basin of attraction of the trivial steady state (Figure 8), after the reduction, the same initial capital distribution ends up in the basin of the high steady state level (Figure 9). However, note that this reduction of diffusion does not preclude the basin of attraction of the trivial steady state to exist: in this last scenario $\left(k(x, 0)=k(x, 0)_{l}\right.$ and $\left.d=d_{l}\right)$, a slight reduction in the parameter $k_{l}$, for example, can lead the economy to the way to collaps 7 . These numerical results clearly show that in an S-shaped technology framework, it is no longer obvious that the spatial economy develops along a sustainable path 8 .
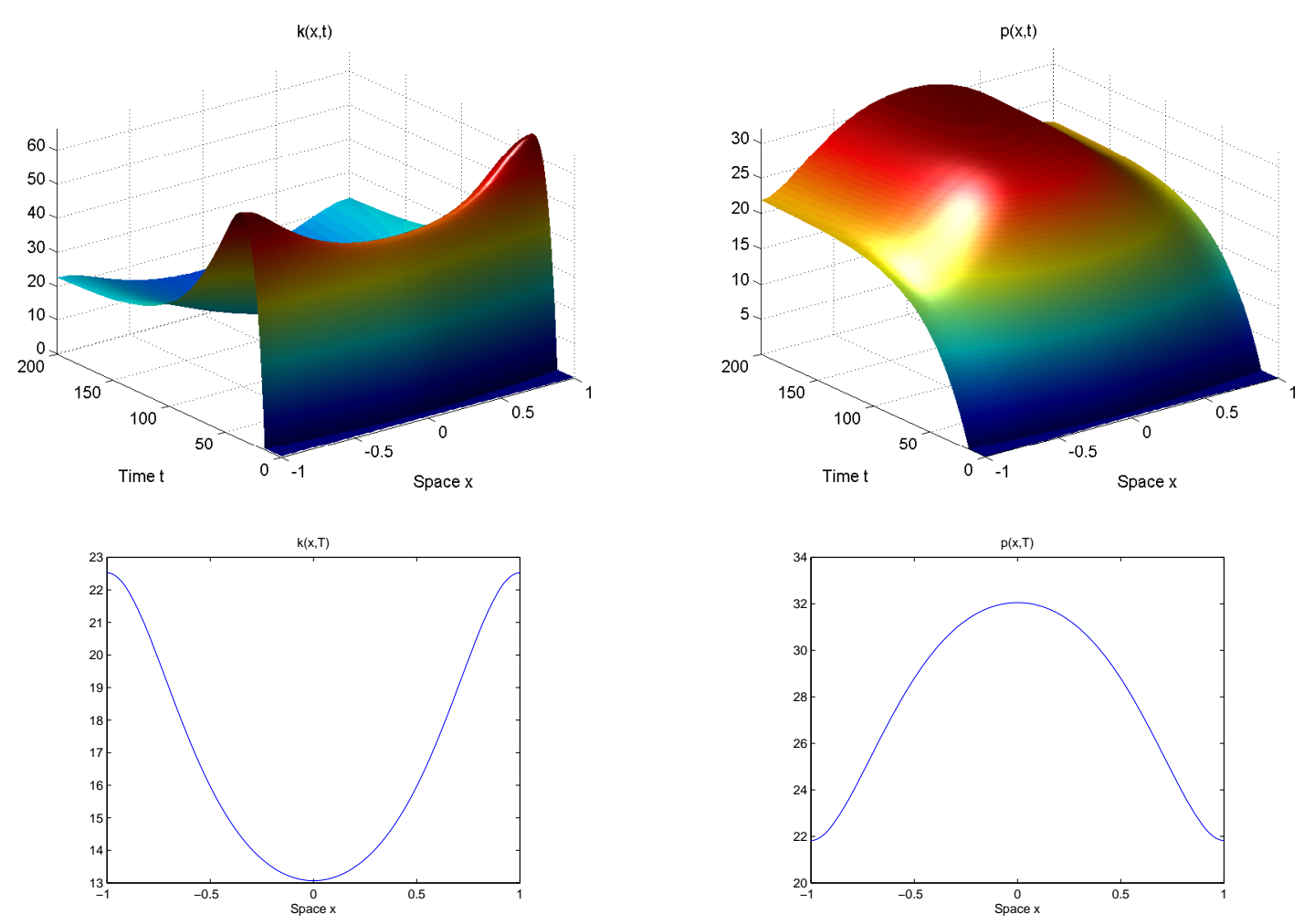

Figure 9: S-shaped production case: evolution of capital and pollution (with $k(x, 0)=k(x, 0)_{l}$ and $d=d_{l}$ ).

By comparing the results obtained under a neoclassical and S-shaped production function, respectively given in (3) and (5), we can understand the main implications of poverty traps on capital and pollution. While collapsing paths are a possible outcome under a convex-concave production function (and they crucially depend on both the initial distribution of capital and the intensity of the diffusion parameters), such a possibility is completely ruled out by the concave Cobb-Douglas technology. Indeed, such a formulation implicitly assumes that the critical capital threshold level coincides with the zero capital level and therefore it has already been exceeded by any living economy. This also means that while under a concave production sustainable development is ensured, this is no longer obvious under a convex-concave production. In reality, only industrialized economies can probably claim to have escaped their poverty traps, and therefore the possibility of observing a collapsing (non-sustainable) outcome, especially in less developed economies, does

\footnotetext{
${ }^{7}$ Ruling out the possibility of poverty traps means essentially to empty the basin of attraction of the trivial steady state, but this cannot be achieved for all the possible values of the parameters. It is surely possible to reduce the size of such a basin of attraction, and in this direction a reduction in the crucial parameter of the damage function, $b$, or in the degree of environmental inefficiency of productive activities, $\theta$, can help. Note that affecting these parameters means intervening on fundamental aspects of the interaction between the economy and the environment.

${ }^{8}$ Note that all the qualitative conclusions discussed thus far in this section hold true even if we use the initial distribution of pollution $p(x, 0)$ rather than the initial distribution of capital. However, if we stick to the reasonable hypothesis that $k(0, x)$ and $p(0, x)$ are proportional that is not a problem. Otherwise, if we think that $k(0, x)$ and $p(0, x)$ are not so simply related, the main conclusion would be similar, but we would need to consider several additional scenarios.
} 
not have to be ruled out a priori.

Finally, let us consider what happens whenever $u(x)$ is not homogeneous across space. We consider the case in which $d=d_{l}$ and $k(x, 0)=k(x, 0)_{h}$ and introduce a linear $u(x)$, as follows: $u(x)=0.5 x+0.5$, meaning that $u$ starts from zero and ends with one, linearly along the domain. We choose this scenario because diffusion is low enough for the structural differences across each location $x$ not to be wiped out. As we can see in Figure 10 the regions close to the left boundary of the domain, that is regions where less attention has been placed on abatement activities, are those with greater long run values for capital, but these higher capital values are achieved at the cost of suffering higher pollution levels. By comparing Figure 7 with Figure 10 we can also see that, in the long run, the maxima and the minima of capital and pollution in the $u$ linear case are respectively greater and lower than the corresponding values in the $u=0.5$ case; this is due to the fact that we have exogenously introduced some heterogeneity in the abatement behavior.
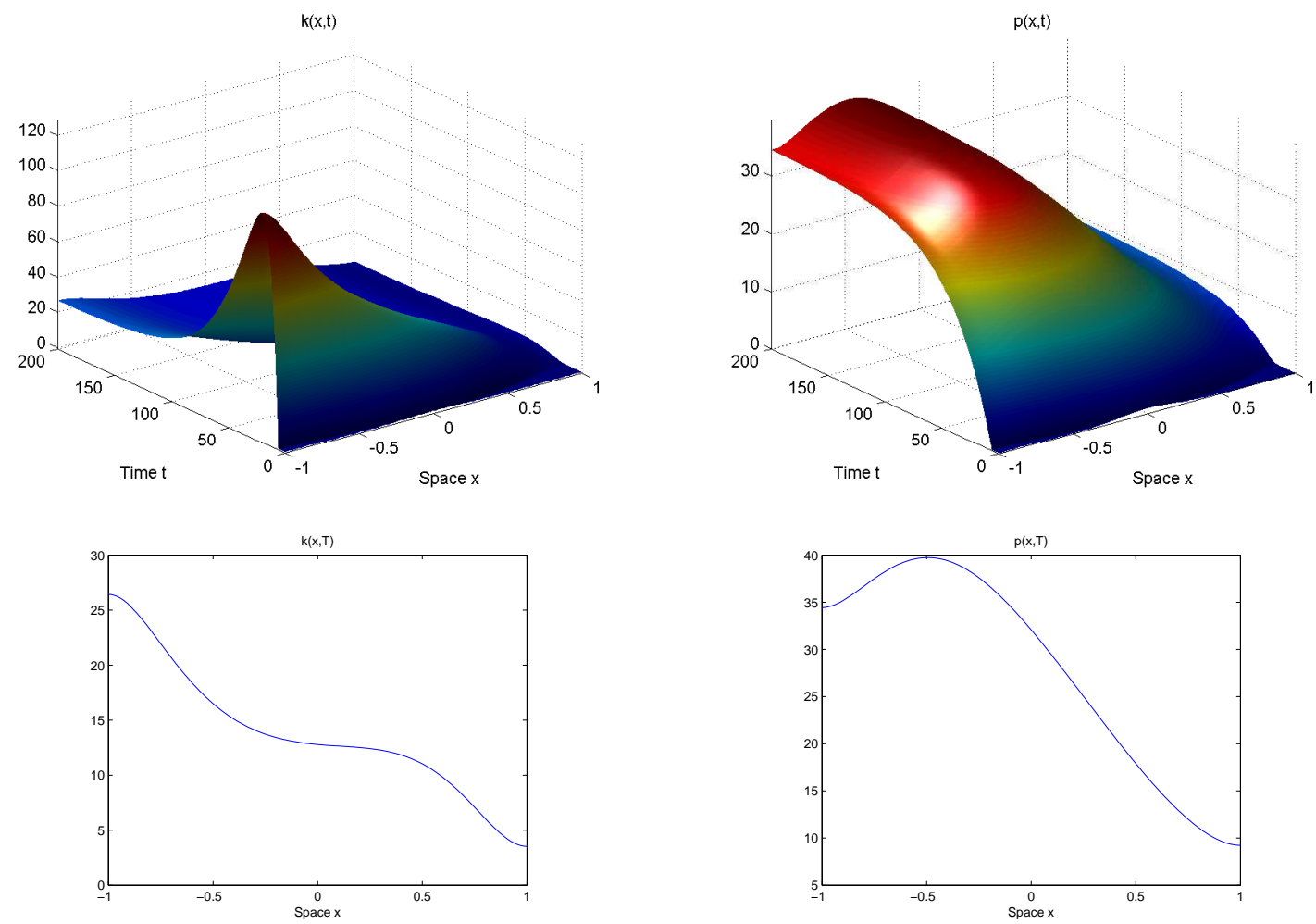

Figure 10: S-shaped production case: evolution of capital and pollution (with $k(x, 0)=k(x, 0)_{h}$ and $d=d_{l}$, along with $u(x)=0.5+0.5 x)$.

\section{The Ramsey-Type Problem}

In this section we wish to relax the behaviorist hypothesis on economic and environmental policies: thus far $s(x)$ and $u(x)$ have been just parameters (though space dependent ones). Now we let them to be optimally chosen by the social planner who by internalizing the spatial externalities selects the optimal spatio-temporal path of consumption $c(x, t)$ and share of abated emissions $u(x, t)$. Hence, as in the canonical Ramsey (1928) 
formulation, the social planner's problem can be expressed as follows:

$$
\begin{aligned}
\max _{c(x, t), u(x, t)} & \int_{0}^{T} \int_{x_{a}}^{x_{b}}\left[c(x, t)-\theta_{p} p(x, t)\right] e^{-\rho t} d x d t \\
\text { s.t. } & \frac{\partial k(x, t)}{\partial t}=d_{1} \frac{\partial^{2} k(x, t)}{\partial x^{2}}+\frac{f[k(x, t)][1-u(x, t)]^{\epsilon}}{a+b p(x, t)^{2}}-\delta_{k} k(x, t)-c(x, t) . \\
& \frac{\partial p(x, t)}{\partial t}=d_{2} \frac{\partial^{2} p(x, t)}{\partial x^{2}}+\theta \int_{x_{a}}^{x_{b}}\left[1-u\left(x^{\prime}, t\right)\right] f\left[k\left(x^{\prime}, t\right)\right] \varphi\left(x^{\prime}, x\right) d x^{\prime}-\delta_{p} p(x, t) .
\end{aligned}
$$

The utility function $U(x, t)=c(x, t)-\theta_{p} p(x, t)$ is separable and linear in consumption and pollution. This formulation can be seen as a generalization of the utility function adopted in Boucekkine et al. (2009), in which we have additionally introduced pollution as a disutility term. The parameter $\theta_{p}$ measures the relative importance of environmental quality with respect to consumption. Differently from Boucekkine et al. (2009), who consider an infinite time horizon, we do not focus on the very long run dynamics of the economic and environmental system, and we consider a finite horizon problem, in which the final horizon represents the amount of time needed to fully unfold environmental policy (e.g., suggested by international agreements). Moreover our model considers a finite domain in the spatial dimension, thus we do not need to introduce a spatial discount factor. It is worth to mention that an approach similar to ours in order to model growth and environmental issues has been suggested by Anita et al. (2013). We however extend their analysis by considering a second control variable, determining the extent of environmental protection activities.

We deal with the optimal control problem above by following the variational method presented in Brock and Xepapadeas $(2008,2010)$. We obtain the generalized current value Hamiltonian function, $\mathcal{H}(k(x, t), p(x, t), u(x, t), c(x, t))$, as follows:

$$
\begin{aligned}
\mathcal{H}= & c(x, t)-\theta_{p} p(x, t)+\lambda_{k}(x, t)\left[d_{k} \frac{\partial^{2} k(x, t)}{\partial x^{2}}+\frac{f[k(x, t)][1-u(x, t)]^{\epsilon}}{a+b p(x, t)^{2}}-\delta_{k} k(x, t)-c(x, t)\right]+ \\
& +\lambda_{p}(x, t)\left[d_{p} \frac{\partial^{2} p(x, t)}{\partial x^{2}}+\theta \int_{x_{a}}^{x_{b}}\left[1-u\left(x^{\prime}, t\right)\right] f\left[k\left(x^{\prime}, t\right)\right] \varphi\left(x^{\prime}, x\right) d x^{\prime}-\delta_{p} p(x, t)\right] .
\end{aligned}
$$

The optimality conditions are:

$$
\begin{aligned}
\frac{\partial \lambda_{k}(x, t)}{\partial t}= & \rho \lambda_{k}(x, t)-d_{k} \frac{\partial^{2} \lambda_{k}(x, t)}{\partial x^{2}}-\lambda_{k}(x, t) \frac{f_{k}[k(x, t)][1-u(x, t)]^{\epsilon}}{a+b p(x, t)^{2}}+\delta_{k} \lambda_{k}(x, t)+ \\
& -[1-u(x, t)] f_{k}[k(x, t)] \theta \int_{x_{a}}^{x_{b}} \lambda_{p}\left(x^{\prime}, t\right) \varphi\left(x^{\prime}, x\right) d x^{\prime} . \\
\frac{\partial \lambda_{p}(x, t)}{\partial t}= & \rho \lambda_{p}(x, t)-d_{p} \frac{\partial^{2} \lambda_{p}(x, t)}{\partial x^{2}}+\theta_{p}+\lambda_{k}(x, t) \frac{2 b p(x, t) f[k(x, t)][1-u(x, t)]^{\epsilon}}{\left[a+b p(x, t)^{2}\right]^{2}}+\delta_{p} \lambda_{p}(x, t),
\end{aligned}
$$

while for the control variables, the maximum principle reads as:

$$
\underset{c(x, t), u(x, t)}{\operatorname{Max}} \mathcal{H}(k(x, t), p(x, t), u(x, t), c(x, t)) .
$$

We need to solve a system of four backward-forward partial differential equations, namely equations (10), (11), (12), (13), where the controls variables $u(x, t)$ and $c(x, t)$ are selected via the maximum principle (14), and the initial conditions on the state variables $k(x, t)$ and $p(x, t)$, the final conditions on the costate 
variables $\lambda_{k}(x, t)$ and $\lambda_{p}(x, t)$ and the Neumann conditions on the first derivatives are given below:

$$
\begin{aligned}
& k(0, x)=k_{0}(x) ; p(0, x)=p_{0}(x) . \\
& k(0, x)=k_{0}(x)=k_{0} e^{-\frac{x^{2}}{k_{0}}} . \\
& p(0, x)=p_{0}(x)=p_{0} e^{x} . \\
& \lambda_{k}(x, T)=0 . \\
& \lambda_{p}(x, T)=0 . \\
& \frac{\partial k\left(x_{a}, t\right)}{\partial x}=\frac{\partial k\left(x_{b}, t\right)}{\partial x}=\frac{\partial p\left(x_{a}, t\right)}{\partial x}=\frac{\partial p\left(x_{b}, t\right)}{\partial x}=0 \forall t \in[0, T] . \\
& \frac{\partial \lambda_{k}\left(x_{a}, t\right)}{\partial x}=\frac{\partial \lambda_{k}\left(x_{b}, t\right)}{\partial x}=\frac{\partial \lambda_{p}\left(x_{a}, t\right)}{\partial x}=\frac{\partial \lambda_{p}\left(x_{b}, t\right)}{\partial x}=0 \forall t \in[0, T] .
\end{aligned}
$$

As in the previous section, we consider two different production functions, the S-shaped and the CobbDouglas ones, with the latter as a benchmark case. With respect to previous section, the only additional conditions we need to impose involve the control variables, and they read as follows:

$$
\begin{aligned}
& 0 \leq c(x, t) \leq f[k(x, t)] \frac{[1-u(x, t)]^{\epsilon}}{a+b p(x, t)^{2}} . \\
& 0 \leq u(x, t) \leq 1 .
\end{aligned}
$$

The condition on consumption in (15) states that gross investment should not be negative at any time and at any location; (16) states instead the obvious condition that the abatement share needs to belong to the closed interval $[0,1]$.

\subsection{Spatio-Temporal Dynamics}

For the numerical solution of our optimal control problem, we rely on a generalization of the Sweep Algorithm (see McAsey et al., 2012; and see also appendix A for further technical details). Finally, the parameters and functions employed in the simulations are the following:

$$
\left\{\begin{array}{l}
\theta=0.2, \epsilon=1, \alpha_{1}=1, \alpha_{2}=1, \theta_{p}=1, x_{a}=-1, x_{b}=1 \\
\delta_{k}=0.001, \delta_{p}=0.05, a=1, b=0.01 \\
A=100, q=4, d_{k}=d_{p}=1, k_{0}=1, p_{0}=1 \\
k(x, 0)=k_{0} e^{-\frac{x^{2}}{k_{0}}}, p(x, 0)=p_{0} e^{x}, \text { and } \varphi\left(x^{\prime} x\right)=\delta\left(x^{\prime}, x\right) .
\end{array}\right.
$$

The choice of the above parameters follows the same clarity purpose as in the previous section. There are minor differences with respect to the initial capital and pollution distribution employed in the previous section, but they do not change our qualitative results.

In the Cobb-Douglas case, as illustrated in Figure 11, the optimal consumption $c$ is zero in any position at the beginning of the planning horizon, while taxation $u$ is at its maximum value, $u=1$. Such an initial outcome persists until, abruptly, the optimal consumption reaches its maximum value and the optimal taxation drops to zero. In other words, it is optimal to keep consumption low and taxation high initially, at any location in the spatial economy, and then do exactly the opposite, as the end of the planning horizon approaches. The optimal controls affect the evolution of the state variables: the high level of initial abatement activities drains resources from the accumulation of capital, which have limited dynamics but ends with a positive steady state for all the regions on the domain. Given the spatial homogeneity of the controls, pollution remains higher in the more initially polluted regions. It is to be noticed that when the optimal policy switches from $c=0$ and $u=1$ to $c=1$ and $u=0$ there is an increase in the level of pollution 

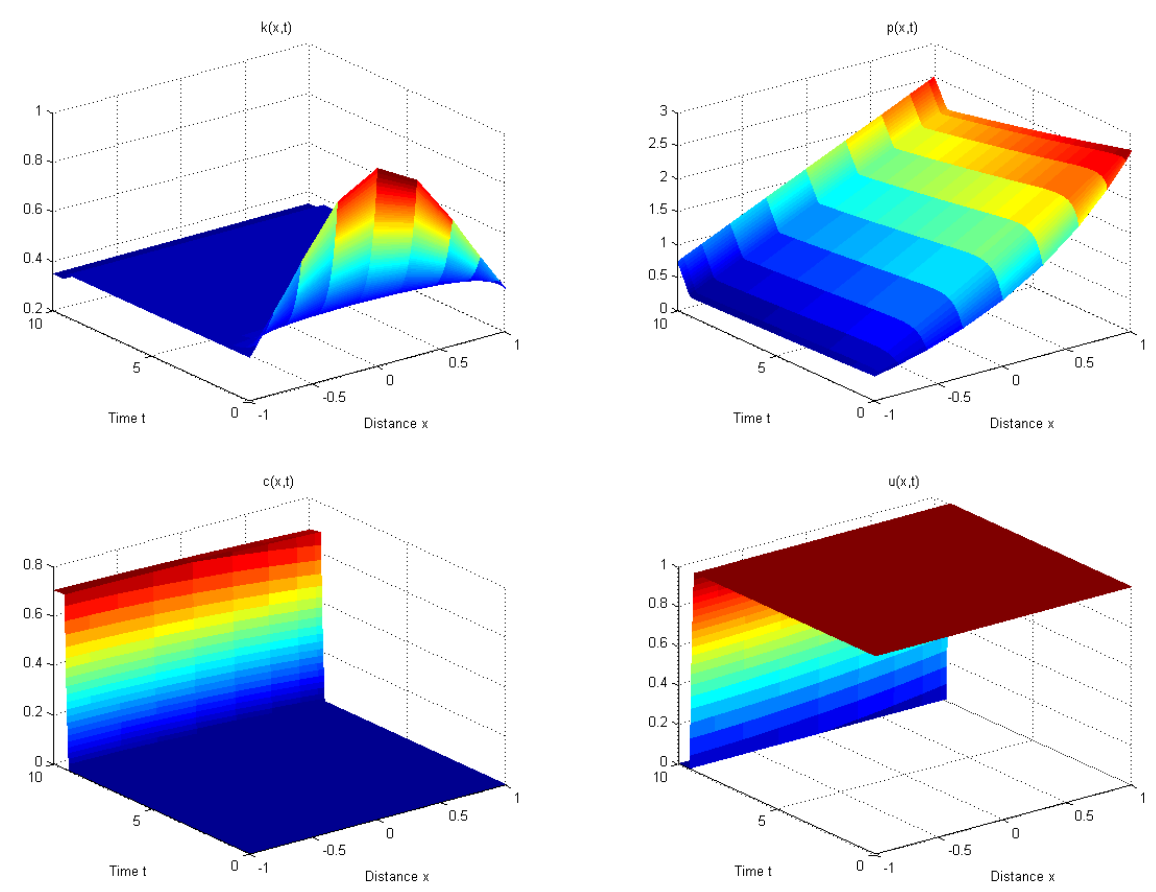

Figure 11: Cobb-Douglas production case: evolution of capital, pollution, consumption and share of abated emissions in the optimally planned case (with $d=1$ and $k_{0}=1$ ).
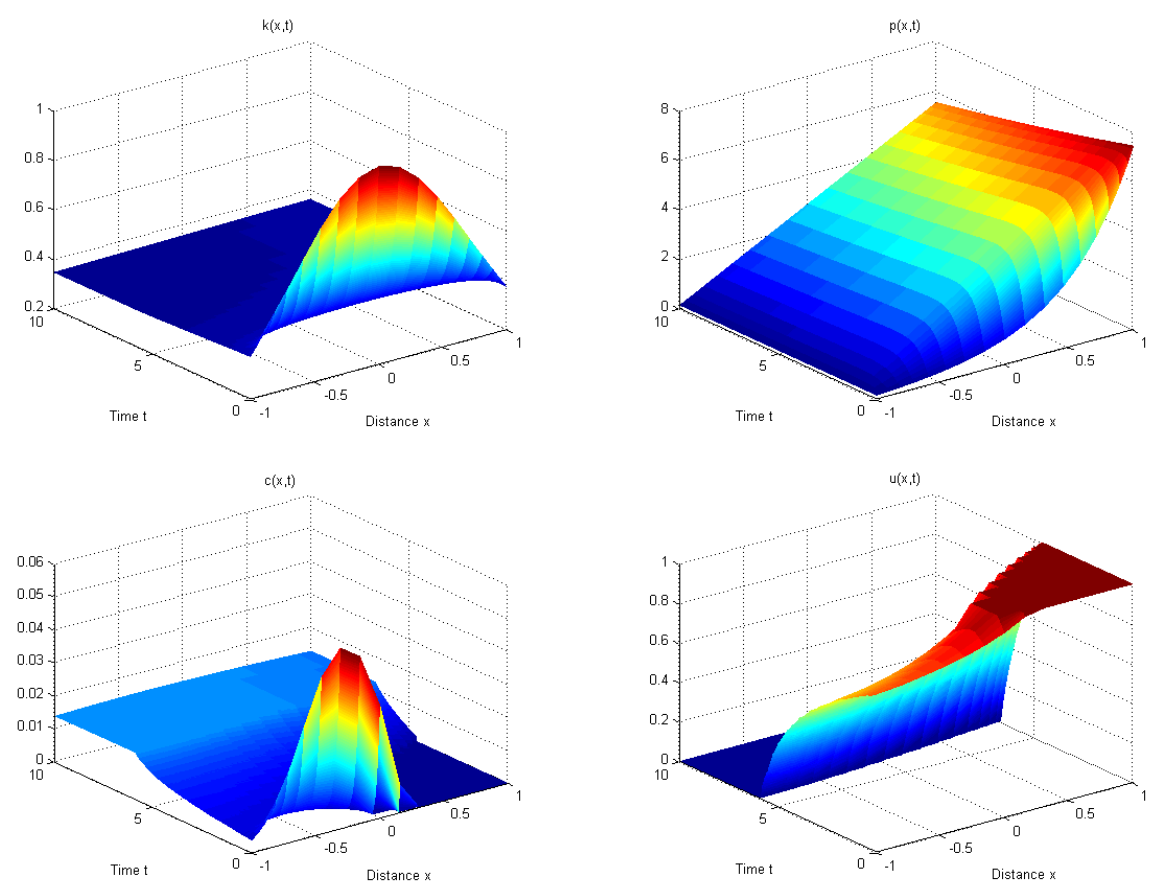

Figure 12: S-shaped production case: evolution of capital, pollution, consumption and share of abated emissions in the optimally planned case (with $d=1$ and $k_{0}=1$ ).

in each region and the opposite happens to the level of capital: of course this is due to the simulataneous change in the optimal policies.

As is it possible to observe in Figure 12, for the S-shaped case, we have a qualitatively similar behavior of the optimal consumption level and abatement rate, but we gain in the spatial heterogeneity: the profiles of 
the optimal policies in space and time show that the regions starting with a higher distribution of pollution $\left(p(0, x)=p_{0} e^{x}, p_{0}=1\right)$ are the last experiencing a reduction in the abatement taxation, from the maximal level, $u=1$, to the minimal level, $u=0$, and, accordingly, the last to appreciate an increase in the optimal consumption policy $c$, from $c=0$ to $c=c(T, x)$. On the contrary, the regions on the left (i.e., the initially least polluted regions), have a starting level of abatement taxation $u<1$, and suffer taxation for a shorter period of time, while the optimal consumption is strictly positive and increasing since the beginning of the planning horizon. As in the previous case, the optimal policies shape the spatio-temporal dynamics of capital and pollution: capital has again limited temporal dynamics but heterogeneous (and positive) spatial profile at the end of the period $T$, where $k(T, x)$ increases with the level of pollution $p(T, x)$ from the left to the right. As before, the level of pollution remains higher in the more initially polluted regions, but in these regions there is actually a decrease in $p$, while the least initially polluted regions pay the price of consumption with a higher final value of $p$. It is important to stress that the spatial economy reaches a positive steady state, meaning that given the parameter values and the initial distribution of capital and pollution, in the optimal control framework policymakers are able to address the economy toward a sustainable outcome. That is not obvious at all in the S-Shaped production function case, as already discussed in the previous section.

\section{Conclusions}

In order to shed some light on how the evolution of capital and pollution interact not only over time but also across space, this paper studies an economic growth model with pollution abatement activities. Specifically we extend the spatial model by Camacho and Zou (2004) and Boucekkine et al. (2009) in order to allow for pollution diffusion (Camacho and Pérez-Barahona, 2015). Our framework introduces a kernel-based approach to modeling the spatial spread of pollution, allowing to distinguish between diffusive and non-diffusive spatial externalities, contrasting the outcomes under a neoclassical and a convex-concave production function. Differently from what happens with a globally concave production function, the case of an S-shaped production technology since allowing for eventual poverty traps exhibits a richer variety of possible scenarios, mainly due to the fact that its evolution operator is non-concave. In addition, the behavior of capital and pollution are dependent upon the initial condition and the diffusivity parameters. In particular, our simulations show that in some cases in the long run the economy survives in the presence of a nonzero bounded level of pollution, but it could even be the case that the presence of a negative pollution feedback on output leads every region in the spatial economy to collapse. We show that in the convex-concave production framework the spatial implications of capital and pollution, thanks to two different channels (namely, diffusion and pollution externality), might allow poor regions to escape their poverty traps (or alternatively, it might condemn also rich regions to collapse in the long run). Specifically, whenever rich regions are substantially rich diffusion can play a very important role in allowing poor regions to escape their poverty traps; if however they are not rich enough diffusion might condemn also rich regions to collapse in the long run. However, even if rich regions are particularly rich but pollution feeds back on economic production strongly enough, the whole spatial economy might be doomed to collapse.

Note that our paper represents only a preliminary attempt to analyze the mutual relationship between capital accumulation and pollution in a spatial framework. However, the problem of sustainable development is much more complex than what we could describe in our model thus further research is definitely needed in order to shed some more light on the potential spatial heterogeneities generated by environmental policies and issues. For example, in our analysis we have not considered the effect of cleaning technological progress, thus it is natural wondering how our results might differ by introducing such a further complication in the joint dynamics of capital and pollution. In particular, the arising of an environmental Kuznets curve (as shown in Brock and Taylor, 2010) which is generally interpreted as a positive outcome for the economic and environmental system could be totally prevented by the diffusion of pollution from highly to lowly polluted 
locations. Thus, in a spatial context the implications of traditional (a-spatial) environmental policies might need to be substantially revised. This challenging task is left for future research.

\section{A Numerical Simulations}

We implement the forward-backward sweep method for the system $(10),(11),(12),(13)$ and $(14)$ as follows:

1. We start by choosing an initial guess $\left(c^{(0)}, u^{(0)}\right)=\left(c^{(0)}(t), u^{(0)}(t)\right)$.

2. Iteration for $j \geq 0$ : by using the spectral method, we solve

$$
\begin{aligned}
& \frac{\partial k^{(j+1)}(x, t)}{\partial t}=d_{k} \frac{\partial^{2} k^{(j+1)}(x, t)}{\partial x^{2}}+\frac{g\left[k^{(j+1)}(x, t)\right]\left[1-u^{(j)}(x, t)\right]^{\epsilon}}{a+b p^{(j+1)}(x, t)}-\delta_{k} k^{(j+1)}(x, t)-c^{(j)}(x, t), \\
& \frac{\partial p^{(j+1)}(x, t)}{\partial t}=d_{p} \frac{\partial^{2} p^{(j+1)}(x, t)}{\partial x^{2}}+\theta \int_{x_{a}}^{x_{b}}\left[1-u^{(j)}\left(x^{\prime}, t\right)\right] f\left[k^{(j+1)}\left(x^{\prime}, t\right)\right] \varphi\left(x^{\prime}, x\right) d x^{\prime}-\delta_{p} p^{(j+1)}(x, t),
\end{aligned}
$$

subject to

$$
\begin{gathered}
k^{(j+1)}(x, 0)=k_{0}(x) \text { in } \Omega, \\
p^{(j+1)}(x, 0)=p_{0}(x) \text { in } \Omega, \\
\frac{\partial k^{(j+1)}(x, t)}{\partial n}=0 \text { on } \partial \Omega, \\
\frac{\partial p^{(j+1)}(x, t)}{\partial n}=0 \text { on } \partial \Omega .
\end{gathered}
$$

We reverse equation $(12)$ and $(13)$ in time, via the change of variable $\bar{t}=T-t$, turning the problem into a forward problem with zero initial conditions. Then, we solve

$$
\begin{aligned}
\frac{\partial \lambda_{k}^{(j+1)}(x, t)}{\partial t}= & \rho \lambda_{k}^{(j+1)}-d_{k} \frac{\partial^{2} \lambda_{k}^{(j+1)}(x, t)}{\partial x^{2}}-\lambda_{k}^{(j+1)}(x, t) \frac{f_{k}\left[k^{(j+1)}(x, t)\right]\left[1-u^{(j)}(x, t)\right]^{\epsilon}}{a+b p^{(j+1)}(x, t)^{2}}+ \\
& +\delta_{k} \lambda_{k}^{(j+1)}(x, t)-\left[1-u^{(j)}(x, t)\right] f_{k}\left[k^{(j+1)}(x, t)\right] \theta \int_{x_{a}}^{x_{b}} \lambda_{p}^{(j+1)}\left(x^{\prime}, t\right) \varphi\left(x^{\prime}, x\right) d x^{\prime} \\
\frac{\partial \lambda_{p}^{(j+1)}(x, t)}{\partial t}= & \rho \lambda_{p}^{(j+1)}-d_{p} \frac{\partial^{2} \lambda_{p}^{(j+1)}(x, t)}{\partial x^{2}}+\theta_{p}+\lambda_{k}^{(j+1)}(x, t) \frac{2 b p^{(j+1)}(x, t) f\left[k^{(j+1)}(x, t)\right]\left[1-u^{(j)}(x, t)\right]^{\epsilon}}{\left[a+b p^{(j+1)}(x, t)^{2}\right]^{2}}+ \\
& +\delta_{p} \lambda_{p}^{(j+1)}(x, t)
\end{aligned}
$$

subject to

$$
\begin{gathered}
\lambda_{k}^{(j+1)}(x, 0)=0 \text { in } \Omega, \\
\lambda_{k}^{(j+1)}(x, 0)=0 \text { in } \Omega, \\
\frac{\partial \lambda_{k}^{(j+1)}(x, \bar{t})}{\partial n}=0 \text { on } \partial \Omega, \\
\frac{\partial \lambda_{k}^{(j+1)}(x, \bar{t})}{\partial n}=0 \text { on } \partial \Omega .
\end{gathered}
$$

Using MATLAB fmincon function (function is used to find the minimum of constrained nonlinear 
multivariable function) defined below

$$
\min _{x} f(x) \text { such that }\left\{\begin{array}{l}
c(x) \leq 0 \\
c e q(x)=0 \\
A \cdot x \leq b \\
A e q \cdot x=b e q \\
l b \leq x \leq u b
\end{array}\right.
$$

to find the value of $c(x, t)$ and $u(x, t)$ that maximize $\mathcal{H}$. We achieve this, by finding the value of $c(x, t)$ and $u(x, t)$ that minimize $-\mathcal{H}$. Finally we check for convergence by computing the difference between the values of $c(x, t)$ and $u(x, t)$ in this iteration and the corresponding ones in the last iteration. If the $\mathcal{L}^{2}$-norm of the difference is negligibly small, we output the current function as solution, otherwise we continue iterating.

\section{References}

1. Anita, S., Capasso, V., Kunze, H., La Torre, D. (2013). Optimal control and long-run dynamics for a spatial economic growth model with physical capital accumulation and pollution diffusion, Applied Mathematics Letters 26, 908-912

2. Bartz, S., Kelly, D.L. (2008). Economic growth and the environment: theory and facts, Resource and Energy Economics 30, 115-149

3. Boucekkine, R., Camacho, C., Zou, B. (2009). Bridging the gap between growth theory and economic geography: the spatial Ramsey model, Macroeconomic Dynamics 13, 20-45

4. Boucekkine, R., Camacho, C., Fabbri, G. (2013a). On the optimal control of some parabolic differential equations arising in economics, Serdica Mathematical Journal 39, 331-354

5. Boucekkine, R., Camacho, C., Fabbri, G. (2013b). Spatial dynamics and convergence: the spatial AK model, Journal of Economic Theory 148, 2719-2736

6. Bovenberg, L., Smulders, S.A. (1995). Environmental quality and pollution-augmenting technological change in a two-sector endogenous growth model, Journal of Public Economics 57, 369-391

7. Brito, P. (2004). The dynamics of growth and distribution in a spatially heterogeneous world, UECEISEG, Technical University of Lisbon

8. Brock, W.A., Taylor, M.S. (2005). Economic growth and the environment: a review of theory and empirics (In: Aghion, P., Durlauf, S., Eds., Handbook of Economic Growth, 1749-1821)

9. Brock, W.A., Taylor, M.S. (2010). The green Solow model, Journal of Economic Growth 15, 127-153

10. Brock, W.A., Xepapadeas, A. (2008). Diffusion-induced instability and pattern formation in infinite horizon recursive optimal control, Journal of Economic Dynamics \& Control 32, 2745-2787

11. Brock, W.A., Xepapadeas, A. (2010). Pattern formations, spatial externalities and regulation in a coupled economic-ecological system, Journal of Environmental Economics and Management 59, 149164

12. Camacho, C., Pérez-Barahona, A. (2015). Land use dynamics and the environment, Journal of Economic Dynamics \& Control 52, 96-118

13. Camacho, C., Zou, B. (2004). The spatial Solow model, Economics Bulletin 18, 1-11

14. Camacho, C., Zou, B., Briani, M. (2008). On the dynamics of capital accumulation across space, European Journal of Operational Research 186 2, 451-465

15. Capasso, V., Engbers R., La Torre, D. (2010). On a spatial Solow model with technological diffusion and non-concave production function, Nonlinear Analysis: Real World Applications, 11(5), 3858-3876 
16. Capasso, V., Maddalena, L. (1982). Saddle point behaviour for a reaction-diffusion system: application to a class of epidemic models, Mathematics and Computers in Simulation 24, 540-547

17. Fujita, M., Krugman, P., Venables, A. (1999). The spatial economy. Cities, regions and international trade (MIT Press).

18. Fujita, M., Thisse, J.F. (2002). Economics of agglomeration (Cambridge University Press)

19. Gradus, R., S. Smulders (1993). The trade-off between environmental care and long-term growth: pollution in three prototype growth models, Journal of Economics 58, 25-51

20. Hotelling, H.(1929). Stability in Competition, Economic Journal 39, 41-57.

21. Kelly, D.L. (2003). On environmental Kuznets curves arising from stock externalities, Journal of Economic Dynamics \& Control 27, 1367-1390

22. Krugman, P. (1991). Increasing returns and economic geography, Journal of Political Economy 99, 483-499

23. Krugman, P. (1993). On the number and location of cities, European Economic Review 37, 293-298

24. Marsiglio, S. (2011). On the relationship between population change and sustainable development, Research in Economics 65, 353-364

25. Marsiglio, S. (2015). Economic growth and environment: tourism as a trigger for green growth, Tourism Economics 21, 183-204

26. McAsey, M., Mou, L., Han, W. (2012). Convergence of the forward-backward sweep method in optimal control, Computational Optimization and Applications 53, 207-226

27. Mora, X. (1983). Semilinear parabolic problems define semiflows on $C^{k}$ spaces, Transactions of the American Mathematical Society 278 1, 21-55

28. Sachs, J.D., McArthur, J.W., Schimdt-Traub, G., Kruk, M., Bahadur, C., Faye, M., McCord, G. (2004). Ending Africa's poverty trap, Brookings Papers on Economic Activity 1, 117-240 (Washington: The Brookings Institution).

29. Saltari, E.,Travaglini, G. (2014). Pollution control under emission constraints: Switching between regimes, Energy Economics, forthcoming, http://dx.doi.org/10.1016/j.eneco.2014.07.010

30. Skiba, A.K. (1978), Optimal growth with a convex-concave production function, Econometrica 46, $527-539$

31. Smulders, S. (1999). Endogenous growth theory and the environment, in (van den Bergh, J., Ed.), "The Handbook of Environmental and Resource Economics" (Edward Elgar: Cheltenham)

32. Solow, R.M. (1956). A contribution to the theory of economic growth, Quarterly Journal of Economics 70, 65-94

33. Solow, R.M. (1974). Intergenerational equity and exhaustible resources, Review of Economic Studies 41, 29-45

34. Stokey, N. (1998). Are there limits to growth?, International Economic Review 39, 1-31

35. UNEP (2012). The future we want - Rio+20 outcome document, available on-line at: http://www.uncsd2012.org/thefuturewewant.html

36. Xepapadeas, A. (2005). Economic growth and the environment, in (Mler, K.G., Vincent, J., Eds.), "Handbook of Environmental Economics", vol. 3. (Elsevier: Amsterdam, Netherlands) 